www.asianjournalofmycology.org Article

Doi 10.5943/ajom/2/1/7

\title{
Fifteen fungicolous Ascomycetes on edible and medicinal mushrooms in China and Thailand
}

\author{
Sun $\mathrm{JZ}^{1,2}$, Liu ${ }^{1} \mathrm{XZ}^{1 *}$, Jeewon $\mathbf{R}^{3}$, Li YL ${ }^{4}$, Lin $\mathrm{CG}^{2}$, Tian $\mathbf{Q}^{2}$, Zhao $\mathbf{Q}^{4}$, Xiao $\mathrm{XP}^{2}$, \\ Hyde $\mathrm{KD}^{2 *}$, Nilthong $\mathrm{S}^{6}$
}

\footnotetext{
${ }^{1}$ State Key Laboratory of Mycology, Institute of Microbiology, Chinese Academy of Sciences, No. 3 Park 1, Beichen West Road, Chaoyang District, Beijing 100101, People's Republic of China

${ }^{2}$ Center of Excellence in Fungal Research, Mae Fah Luang University, Chiang Rai, 57100, Thailand

${ }^{3}$ Department of Health Sciences, Faculty of Science, University of Mauritius, Reduit, Mauritius

${ }^{4}$ Grassland Research Institute, Qinghai Academy of Animal Sciences and Veterinary Medicine, Qinghai Xining 810016, People's Republic of China

${ }^{5}$ Key Laboratory for Plant Diversity and Biogeography of East Asia, Kunming Institute of Botany, Chinese Academy of Sciences, Kunming 650201, People's Republic of China

${ }^{6}$ School of Science, Mae Fah Luang University, Chiang Rai 57100, Thailand
}

Sun JZ, Liu XZ, Jeewon R, Li YL, Lin CG, Tian Q, Zhao Q, Xiao XP, Hyde KD, Nilthong S 2019 - Fifteen fungicolous Ascomycetes on edible and medicinal mushrooms in China and Thailand. Asian Journal of Mycology 2(1), 129-169, Doi 10.5943/ajom/2/1/7

\begin{abstract}
Edible and medicinal mushrooms are extensively cultivated and commercially consumed in many countries, especially in China and Thailand. A number of fungicolous fungi could cause deformation or decomposition of mushrooms. Investigation of taxonomic diversity and exact identification are initial and crucial steps to understand interactions between fungicolous taxa and their hosts as well as to propose better disease management strategies in the mushroom industry. In this study, during a survey of fungicolous fungi on eight edible and medicinal mushrooms from mushroom farms and from the wild in China and Thailand, 15 taxa were identified based on morphological characteristics and DNA sequence data analyses. Three new species, including Sporothrix ganoderma (Ophiostomatales) on cultivated Ganoderma lucidum in China; Hypomyces fistulina (Hypocreaceae) on Fistulina species in China; and Hypomyces boletus on Boletus species in Thailand are described and introduced here. Other species recovered from China include Aspergillus pseudoglaucus (Trichocomaceae) on a wild Helvella species; Fusarium sonali (Nectriaceae) on cultivated Morchella importuna; Clonostachys rosea f. catenulata (Bionectriaceae) and Paecilomyces hepiali (Cordycipitaceae) on cultivated Ophiocordyceps sinensis; Polycephalomyces sinensis (Ophiocordycipitaceae) on wild Ophiocordyceps sinensis; Lecanicillium fungicola var. aleophilum (Cordycipitaceae) and Hypomyces rosellus on cultivated Agaricus bisporus; Paecilomyces formosus (Trichocomaceae) on Fistulina; Hypomyces aurantius (Hypocreaceae) on Panellus species; Trichoderma atrobrunneum (Hypocreaceae) on cultivated Ganoderma lucidum. Hypomyces boletiphagus (Hypocreaceae) on Boletus sp. and Cladobotryum protrusum (Hypocreaceae) were recovered on a decayed mushroom from Thailand. This study enriches our current taxonomic knowledge on the diversity of fungicolous fungi in these regions.
\end{abstract}

Key words - 3 new taxa - caterpillar fungi - fungal disease - mycoparasites - Hypomyces 


\section{Introduction}

Mushrooms have been consumed for their nutritive and medicinal values (Zhang et al. 2015, Dong et al. 2015). The production of mushrooms in China accounts for $70 \%$ of the world yield, while $1 \%$ is contributed by Thailand (Zhang et al. 2015). Among these edible and medicinal mushrooms, Agaricus bisporus and Ganoderma lucidum are two of the most popular species cultivated and consumed in China and Thailand (Poomsing et al. 2013, Zhang et al. 2015). Morchella importuna and Ophiocordyceps sinensis are another two valuable species, which are usually collected in the field but currently are domesticated and cultivated in mushroom farms (Dong et al. 2015, Du et al. 2015, Zhang et al. 2015). Boletoid basidiomycetes are collected and consumed by collections of fresh fruiting bodies in the field (Zhang et al. 2015, Wu et al. 2016). However, the yield and quality of mushrooms are often reduced by infestations of fungicolous fungi (Fletcher \& Gaze 2007, Tamm \& Põldmaa 2013, Carrasco et al. 2016, 2017, Sun et al. 2016, 2019).

Fungicolous fungi are an important ecological group, acting as symbionts (including parasites and saprobes) associated with other fungi (Gams et al. 2004, Sun et al. 2019). This relationship has evolved across different lineages within the fungal kingdom (Põldmaa 2011). Fungicolous Ascomycota is a very taxonomically diverse group of fungicolous fungi (Gams et al. 2004, Zhu \& Zhuang 2013, Sun et al. 2019). Previous studies reported that fungicolous fungi (mycoparasites) on mushrooms are more diverse within Sordariomycetes, mostly in the order Hypocreales (Põldmaa 2000, 2011, Zhu \& Zhuang 2013, Zhang et al. 2018, Sun et al. 2017, 2019). Most taxa belong to Bionectriaceae, Calcarisporiaceae, Cordycipitaceae, Hypocreaceae, and Nectriaceae, (Sung et al. 2007, Zare \& Gams 2008, Rossman et al. 2013, Wijayawardene et al. 2017a, b, Sun et al. 2017, 2019). Hypomyces (Fr.) Tul. \& C. Tul. (Hypocreaceae) is the largest fungicolous genus, and members parasitize agaricomycetes from temperate to tropical regions (Rogerson \& Samuels 1989, 1993, 1994, Põldmaa 2000, 2011, Tamm \& Põldmaa2013). Trichoderma Pers. (Hypocreaceae) comprises many fungicolous species colonizing other fungi, causing green mold disease in cultivated mushrooms (Hatvani et al. 2007, Kim et al. 2013, Bissett et al. 2015, Jaklitsch \& Voglmayr 2015). Lecanicillium W. Gams \& Zare usually associated with insects and some species are obligate fungicolous of Agaricus, especially cultivated ones (Zare \& Gams 2008). Species from the Ophiostomatales are usually associated with beetles inhabiting freshly fallen trees resulting in blue stain disease of wood, and are reported as opportunistic human pathogens and occasionally colonize species of Ganodermataceae (De Beer et al. 2013, 2016). There are several fungicolous Eurotiomycetes such as Aspergillus and Paecilomyces found on mushrooms or on mushroom composts as competitors or saprobes (Luangsa-ard 2004, Petrović et al. 2013).

Fungicolous fungi have been studied for more than two centuries (Gams et al. 2004, Sun et al. 2019). However, the diversity of fungicolous fungi has not received explicit attention, especially the diversity of fungicolous taxa associated with edible and medicinal mushrooms in China and Thailand. The objectives of this study are as follows: to document fungicolous taxa on the edible and medicinal mushroom in China and Thailand; to identify them by using morphological and phylogenetic approaches.

\section{Materials \& Methods}

Medicinal and edible mushrooms were collected from China and Thailand. Specimens are deposited in the Herbarium Mycologicum Academiae Sinicae (HMAS, Beijing, China). Pure cultures were obtained using single spore isolations following the method described by Chomnunti et al. (2014). Germinated spores were transferred aseptically to malt extract agar (MEA) and incubated at $20^{\circ} \mathrm{C}$ for one or two weeks. Living cultures are deposited at the Mae Fah Luang University Culture Collection (MFLUCC), or in China General Microbiological Culture Collection Center (CGMCC). Index Fungorum numbers were obtained following Index Fungorum (http://www.indexfungorum.org/, 2019). Faces of fungi numbers were registered as in Jayasiri et al. (2015). New taxa are introduced based on the recommendations of Jeewon \& Hyde (2016). 


\section{Morphological studies}

Samples were examined by a Zeiss Discovery V8 Axio Cam ERc 5s stereoscope. Microscopic observations were made from preparations mounted in 50\% lactic acid and measurements in a water mount which were determined with a Nikon Eclipse 80i compound microscope fitted with a Canon 450D digital camera. The statistics presented here are based on the measurement of 30 mature conidia and 30 phialides. Conidiophores were derived from the visible fascicles from the surface of fruiting of mushroom and cultures.

\section{DNA extraction, PCR and sequencing}

Mycelia (5-10 mg) of fungicolous fungi were harvested from 10-day-old cultures or fruiting body of hosts, then placed in $1.5 \mathrm{~mL}$ Eppendorf tubes for genomic DNA extraction. DNA was extracted using a Genomic DNA Extraction Kit (Tiangen Corp, Beijing, China) following the instruction manual. Sequences of internal transcribed spacer (ITS), partial large-subunit ribosomal RNA (LSU), partial small-subunit ribosomal RNA (SSU), translation elongation factor 1 alpha (TEF1- $\alpha$ ), the second largest subunit of RNA polymerase II (RBP2), calmodulin (CaM) and $\square$ tubulin (TBU) genes were amplified by polymerase chain reaction (PCR) with the primer pairs of ITS5 - ITS4 (White et al. 1990), LR5F - LROR (Bhattacharya et al. 2000), NS1 - NS4 (White et al. 1990), EF1-983F - EF1-2218R (Rehner \& Buckley 2005) and RPB2-5F - RPB2-7cR (Liu et al. 1999), LCALM -RCALM (Burns et al. 2005) and T1 and T22 (Schroers 2001) respectively. Each amplification reaction included $0.2 \mathrm{mM}$ of each dNTP, $0.4 \mathrm{mM}$ of each primer, $0.5 \mathrm{U}$ of Taq polymerase (TransGen, China), $2 \mu \mathrm{L}$ of genomic DNA solution, $10 \times$ Easy Taq buffer (Tiangen Corp, Beijing, China) in $25 \mu \mathrm{L}$ reaction volume. A reaction included an initial denaturation at 95 ${ }^{\circ} \mathrm{C}$ for $5 \mathrm{~min}$; followed by 38 cycles of denaturation at $95^{\circ} \mathrm{C}$ for $50 \mathrm{~s}$, annealing at $52{ }^{\circ} \mathrm{C}$ for $70 \mathrm{~s}$ for SSU, LSU, RBP2 and TUB genes, $54{ }^{\circ} \mathrm{C}$ for $50 \mathrm{~s}$ for ITS, $55^{\circ} \mathrm{C}$ for $60 \mathrm{~s}$ for TEF and CaM, extension at $72{ }^{\circ} \mathrm{C}$ for $60 \mathrm{~s}$ and a final extension at $72{ }^{\circ} \mathrm{C}$ for $10 \mathrm{~min}$. PCR products were purified using Gel Product Purification Kit (Tiangen Corp, Beijing, China) according to the manual and sequenced by the service Sino Geno Max Co., Ltd. (Beijing, China).

\section{Phylogenetic analyses}

Sequence data for relevant strains were downloaded from GenBank following data from recent publications (O’Donnell 2000, Zare \& Gams 2008, Samson et al. 2009, Kim et al. 2013, Tamm \& Põldmaa 2013, Abreu et al. 2014, Chaverri et al. 2015, De Beer et al. 2016, Wang et al. 2015, Visagie et al. 2017). Each single gene sequence was aligned using MAFFT ver. 7.03 with the Q-INS-I strategy (Katoh \& Standley 2013). The ambiguous areas of alignment were located and removed using Gblocks 0.91b (Castresana 2000). The appropriate nucleotide substitution model for each gene was tested via the Akaike Information Criterion (AIC) with jModelTest v. 3.7 (Posada $2008)$ and the best-fit model $(\mathrm{GTR}+\mathrm{G}+\mathrm{I})$ was obtained. Genes were combined using SequenceMatrix 1.7.8 (Vaidya et al. 2011).

Maximum-likelihood (ML) analysis was performed in RAXMLGUI ver. 1.3 (Silvestro \& Michalak 2012) with default settings $(G T R+G+I)$ with rapid bootstrap analysis. Bootstrap support (BS) values were inferred based on bootstrap pseudo-replicates with 1,000 replicates, with values equal to or greater than $70 \%$ considered indicative of strong support. Bayesian inference (BI) analyses were calculated in MrBayes v. 3.2.2 (Ronquist et al. 2012), with 2,000,000 generations and four incrementally heated chains. Markov Chain Monte Carlo sampling (MCMC) analysis started from a random tree that was sampled every $100^{\text {th }}$ generation. The average standard deviation $<0.01$ for split frequencies was used to suggest a convergence between parallel runs. The first 25 $\%$ of total trees were discarded as burn-in, and the remaining trees in each analysis were utilized to suggest calculating posterior probabilities (PP) in the majority-rule consensus tree. Bayesian posterior probability (BYPP) was greater than or equal to 0.95 considered indicative of strong support. Trees were figured in FigTree ver. 1.4.2 (Rambaut 2014) and edited in Adobe Illustrator CS6 (Adobe Systems Inc., United States). 
For those three new species proposed, the phylogenetic trees are presented herein and are labeled with species and isolates/culture collection codes as provided in GenBank (Figs 1, 2). Two DNA sequence datasets were analyzed. The first one is a concatenated dataset of ITS, LSU, RPB2, and TEF to determine the placement of two new Hypomyces species. The second dataset includes ITS and LSU which is utilized to determine the relationships of Sporothrix ganoderma, a new species. For the other species which have been described, phylogenetic analyses were also performed and phylogenetic relationships are discussed in the notes sections under each species. All new sequence data generated in this study are deposited in GenBank and the accession numbers are provided.

\section{Results and Discussion}

\section{Phylogenetic analyses}

In this phylogenetic analysis, we include all available sequences of Cladobotryum, Hypomyces, Mycogone, and Sepedonium. The final concatenated dataset containing 142 ingroup taxa and three outgroup taxa, with 3350 characters including gaps (831 characters for LSU, 529 for ITS, 1069 for RPB2, and 921 for TEF). Tree topology of the RAxML analysis was basically similar to the Bayesian analysis. The RAxML analysis yielded the best scoring tree with a final optimization likelihood value of 28795.085203. Support values of ML and BI analyses (equal to or higher than 70\% for BSML and 0.95 for BYPP) are shown in Fig. 1. The tree was rooted with Trichoderma viride (CBS 119325), Trichoderma hamatum (DAOM 167057) Trichoderma harzianum (CBS 226.95).

In the phylogenetic tree, species of Hypomyces and allied asexual genera group together well supported (100\% BSML / 100 BYPP), but are separated into three main clades (Fig. 1). Clade 1 contains most species of Hypomyces which with Cladobotryum and Sepedonium asexual morph. Clade 2 and Clade 3 comprise several species of Hypomyces which with Cladobotryum and Mycogone asexual morph. All of our collections of Hypomyces are positioned in clade 1 . The two new species are all monophyletic with a strong support value: Hypomyces fistulina (100\% BSML / 100 BYPP) and Hypomyces boletus (100\% BSML / 100 BYPP). In addition, Hypomyces fistulina is closely related to Hypomyces aurantius, Cladobotryum gracile, Cladobotryum croceum, and Hypomyces siamensis but weak support (Fig. 1). Hypomyces boletus is closely related to

Hypomyces chrysospermus, Sepedonium laevigatum, and Sepedonium tulasneanum but weak support as well. The other collections of Cladobotryum protrusum, Hypomyces rosellus, Hypomyces aurantius, and Hypomyces boletiphagus cluster together with available strains of each species, respectively (Fig. 1).

The combined LSU and ITS dataset contains 76 taxa of Sporothrix, Ophiostoma, and two taxa of Fragosphaeria. The data matrix comprises 1234 characters including 535 characters of ITS and 699 characters of LSU. Fragosphaeria purpurea and F. reniformis were set as the out-group, and the best-scoring ML tree is shown here (Fig. 2). Tree topology of the RAxML analysis was similar to the Bayesian analysis. The best scoring RAxML tree with the final optimization had a likelihood value of -9336.935954.

In the phylogenetic tree, species of Sporothrix form five main clades strongly supported by Bayesian posterior probabilities except clade 5. Our collections of Sporothrix are positioned in clade 4 (Fig. 2). The collections of Sporothrix ganodrema form a well-supported independent branch (96\%, BSML/1.00, BYPP) and closely related to Sporothrix nebularis complex in Clade 4 (75\% BSML, 1.00 BYPP). 


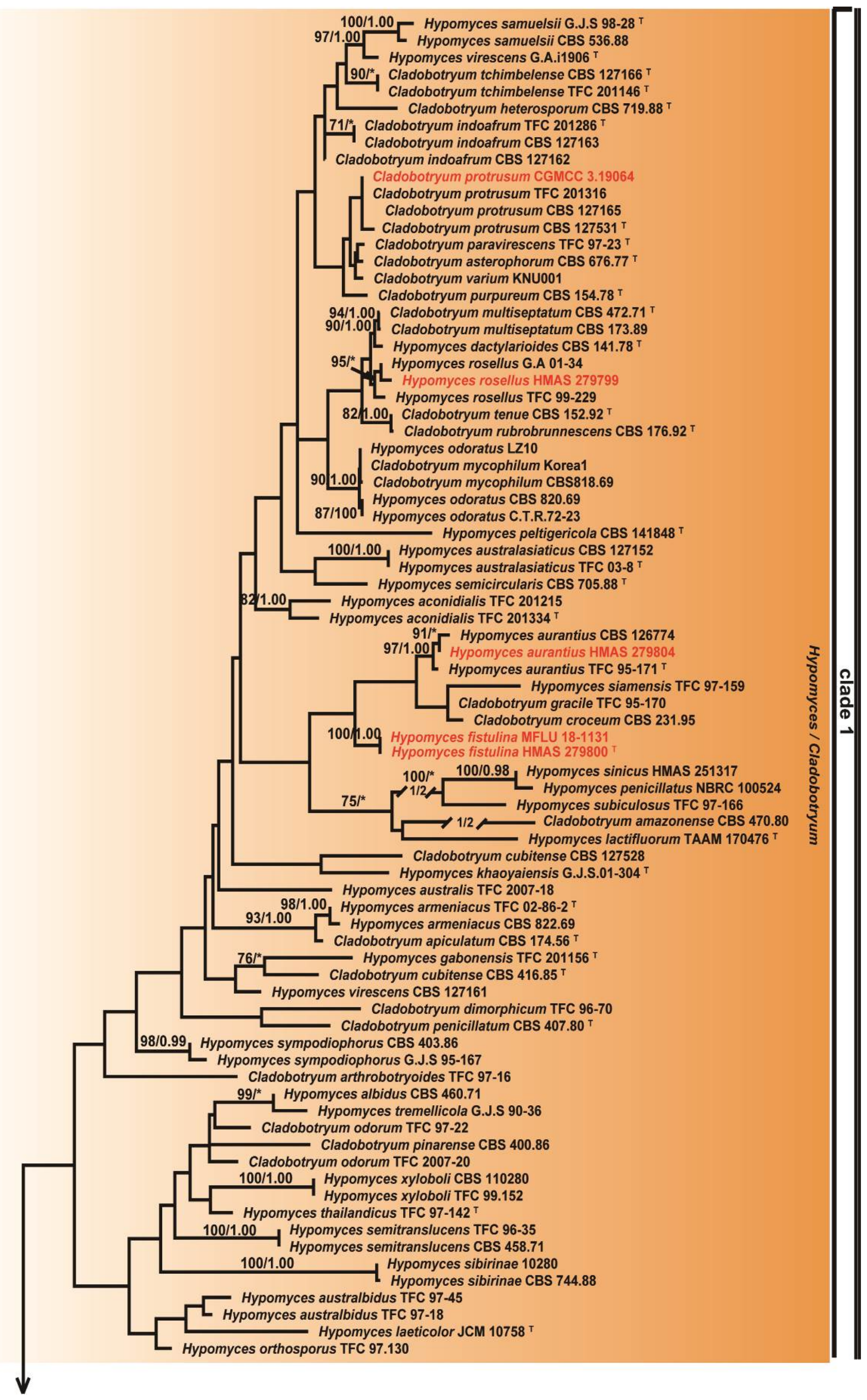




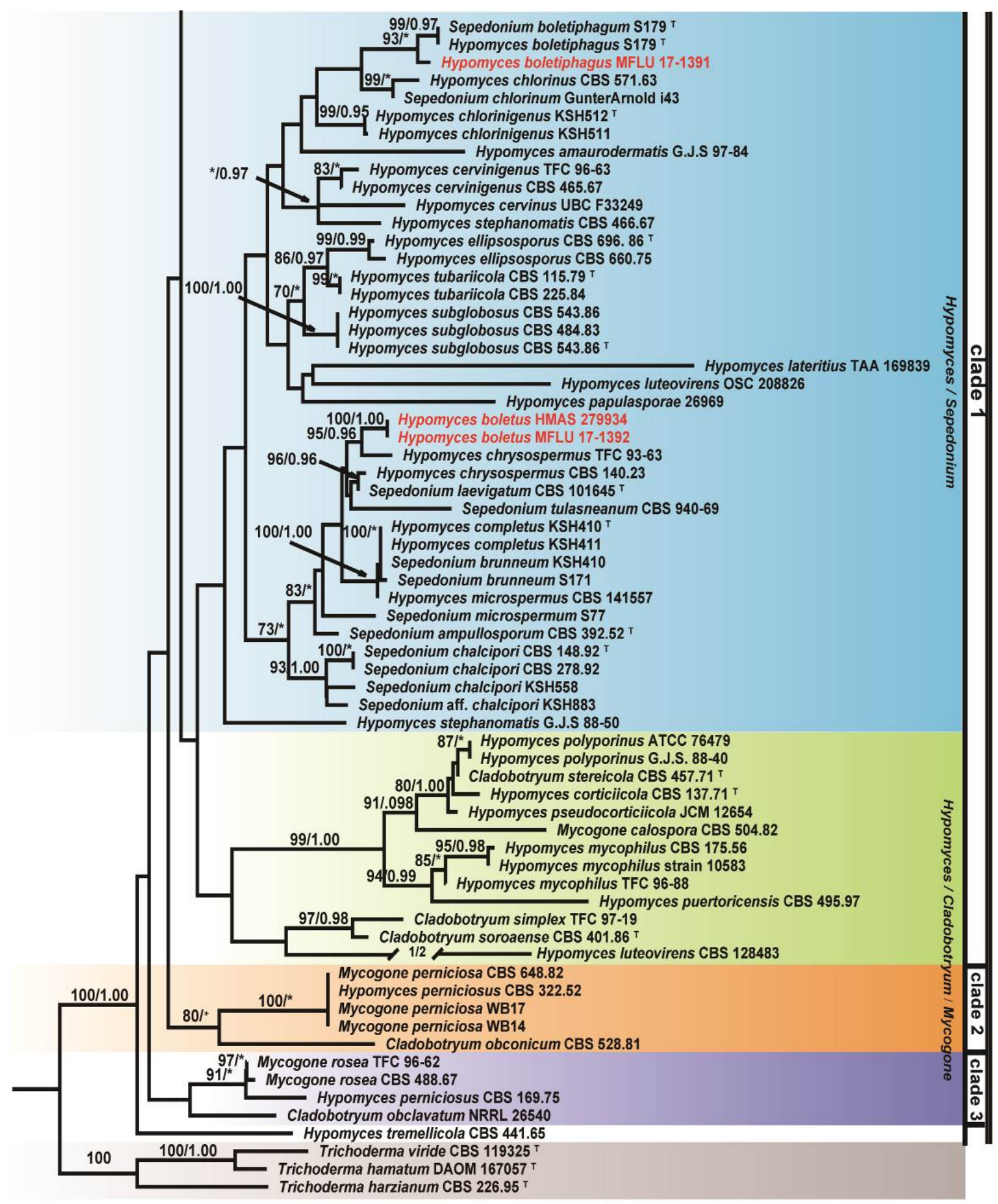

Fig. 1 - Phylogram generated by maximum likelihood analysis based on a combination of ITS, TEF, RPB2 sequence data. The tree is rooted with Trichoderma viride, Trichoderma hamatuma, and Trichoderma harzianum. Bootstrap values higher than 50\% from RAxML (BSML) (left) are given above the nodes. Bayesian posterior probabilities greater than 0.95 are indicated (BYPP) (right). Asterisks indicate bootstrap values of less than $50 \%$ or Bayesian posterior probabilities lower than 0.95. ${ }^{\mathrm{ET}}$ indicates living ex-type. Our fungi are in red font. 


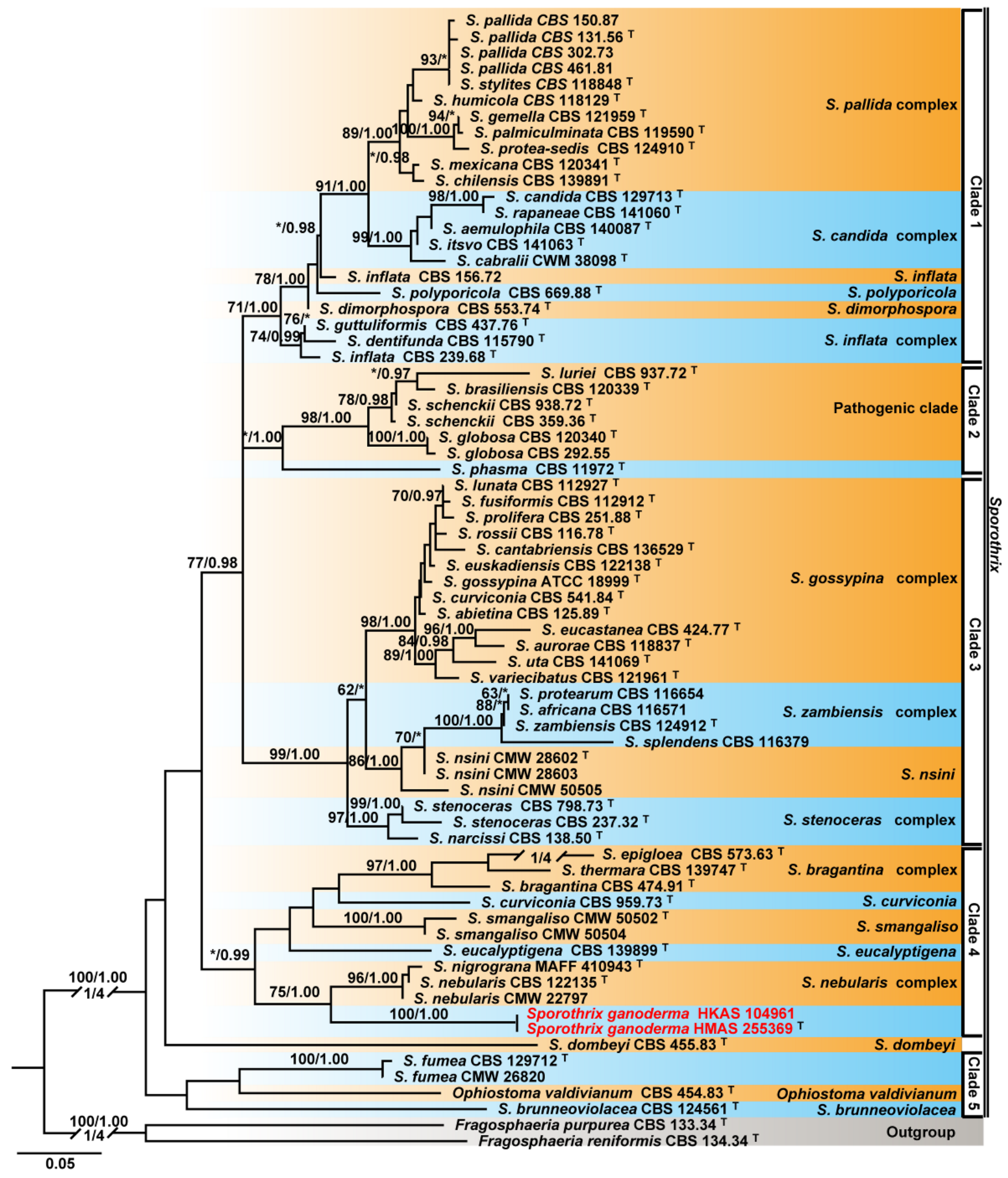

Fig. 2 - Phylogram generated by maximum likelihood analysis based on a combination of LSU and ITS sequence data. The tree is rooted with Fragosphaeria purpurea and Fragosphaeria reniformis. Bootstrap values higher than 50\% from RAxML (BSML) (left) are given above the nodes. Bayesian posterior probabilities greater than 0.95 are indicated (BYPP) (right). Asterisks indicate bootstrap values of less than $50 \%$ or Bayesian posterior probabilities lower than $0.95 .{ }^{\mathrm{T}}$ indicates type. Our fungus is in red font.

\section{Taxonomy}

Aspergillus pseudoglaucus Blochwitz, Annales Mycologici 27(3-4): 207 (1929)

Fig. 3 
$\equiv$ Eurotium pseudoglaucum (Blochwitz) Malloch \& Cain, Canadian Journal of Botany 50(1): $64(1972)$

$\equiv$ Eurotium repens var. pseudoglaucum (Blochwitz) Kozak., Mycological Papers 161: 76 (1989)

Facesoffungi number: FoF 06010

Description from the type specimen, please see detail in Chen et al. (2017).

Saprophytic, fungicolous. Asexual morph: Conidiophores with smooth stipes, hyaline or light brown, $500-1000 \times 11-22 \mu \mathrm{m}(\bar{x}=750 \times 16 \mu \mathrm{m}, \mathrm{n}=20)$. Vesicles globose to subglobose, 37-65 $\mu \mathrm{m}(\bar{x}=55 \mu \mathrm{m}, \mathrm{n}=10)$ wide (degenerated smaller vesicles measuring $11-21 \mu \mathrm{m}(\bar{x}=18 \mu \mathrm{m}, \mathrm{n}=$ $20)$, fertile over two thirds to entire surface. Phialides flask-shaped, 6-11 × 4-6.5 $\mu \mathrm{m}(\bar{x}=9 \times 5.5$ $\mu \mathrm{m}, \mathrm{n}=20$ ). Conidia globose to subglobose, in most strains tuberculate, microtuberculate $6-9 \times$ 5.5-7.5 $\mu \mathrm{m}(\bar{x}=7 \times 6 \mu \mathrm{m}, \mathrm{n}=30)$. Sexual morph: undetermined.

Material examined - THAILAND, Chang Rai Province, Mae Fah Luang University, on a fruiting body of Helvella sp. 20 January 2014; Zhao Q. Living culture MFULCC 14-0336). GenBank no. (ITS: MH459148, CaM: MH464776)

Notes - Aspergillus pseudoglaucus was revised and affiliated in Aspergillus section Aspergillus. Morphologically, A. pseudoglaucus resembles A. proliferans and A. ruber in ascospore size and ornamentation, however, the ascospores of $A$. pseudoglaucus do not have or have indefinite furrow, while $A$. proliferans and $A$. ruber have more pronounced furrow on ascospores (Chen et al. 2017). Our collection produces the Aspergillus-like conidiophores and tuberculate conidia (Fig. 3), which are similar to that of A. pseudoglaucus. The ITS sequence also hits a high similarity to that of $A$. pseudoglaucus. However, ITS sequence is unable to distinguish $A$. pseudoglaucus from closed relatives while CaM sequence performs well in determining species in Aspergillus section Aspergillus (Chen et al. 2017). Herein, phylogenetic analysis based on CaM presents that our collection clusters with all $A$. pseudoglaucus strains include the type strain with strong support (100\% BSML, 1.00 BYPP, Fig. S1). Therefore, based on the phylogeny and morphological characters, our isolate also represents A. pseudoglaucus. This fungus has been isolated from food, paper, tea, as well as air (Chen et al. 2017, Visagie et al. 2017). Aspergillus pseudoglaucus is reported here as a fungicolous taxon for the first time.

Clonostachys rosea f. catenulata (J.C. Gilman \& E.V. Abbott) Schroers, Studies in Mycology 46: 69 (2001)

Fig. 4

$\equiv$ Gliocladium catenulatum J.C. Gilman \& E.V. Abbott, Journal of Iowa State College, Sci. 1(3): 303 (1927)

Facesoffungi number: FoF 06012

Description from the type specimen, please see detail in Schroers (2001)

Fungicolous on cotton layer on the sclerotium of Ophiocordyceps sinensis. Asexual morph: Conidiophores septate, branched, hyaline, smooth-walled. Phialides hyaline, in whorls of 2-5, 25$40 \mu \mathrm{m}(\bar{x}=32.5 \mu \mathrm{m}, \mathrm{n}=20)$ long, $2.0-2.5 \mu \mathrm{m}(\bar{x}=2.2 \mu \mathrm{m}, \mathrm{n}=30)$ wide at base, $1-2 \mu \mathrm{m}(\bar{x}=1.8$ $\mu \mathrm{m}, \mathrm{n}=30)$ wide near aperture. Secondary conidiophores phialides, wide near aperture, $10-15 \mu \mathrm{m}$ ( $\bar{x}=12.6 \mu \mathrm{m}, \mathrm{n}=30)$ long, $2.0-2.5 \mu \mathrm{m}(\bar{x}=2.2 \mu \mathrm{m}, \mathrm{n}=30)$ wide at base, $2.5-3.0 \mu \mathrm{m}(\bar{x}=2.8$ $\mu \mathrm{m}, \mathrm{n}=30)$ at widest point, $1-1.5 \mu \mathrm{m}(\bar{x}=1.3 \mu \mathrm{m}, \mathrm{n}=30)$. Conidia hyaline, aggregated in slimy and hyaline masses, hyaline, minutely curved, distally broadly rounded or slightly tapering, with a laterally displaced hilum, $4.5-5.5 \times 2.5-3.0 \mu \mathrm{m}(\bar{x}=5.1 \times 2.8 \mu \mathrm{m}, \mathrm{n}=30)$. Sexual morph: Undetermined.

Material examined - CHINA, Guang Dong Province, Dong Guan city, on a fruiting body of cultivated Ophiocordyceps sinensis. 12 December 2015; Liu X. Z. (HMAS 281238), living culture CGMCC 3.19064. GenBank no. (ITS: MH459148, TUB: MH464775)

Notes - Clonostachys rosea f. catenulata was introduced as a new combination to accommodate Gliocladium catenulatum J.C. Gilman \& E.V. Abbott (Schroers 2001). Our fungus produces Clonostachys-like conidiophores and conidia (Fig. 4), which is morphologically similar to $C$. rosea and Clonostachys rosea $\mathrm{f}$. catenulata. The ITS sequence also shows a close affinity to 
Clonostachys rosea and Clonostachys rosea f. catenulata. The TUB sequence data could clearly distinguish Clonostachys rosea f. catenulata from C. rosea (Schroers 2001, Abreu et al. 2014).
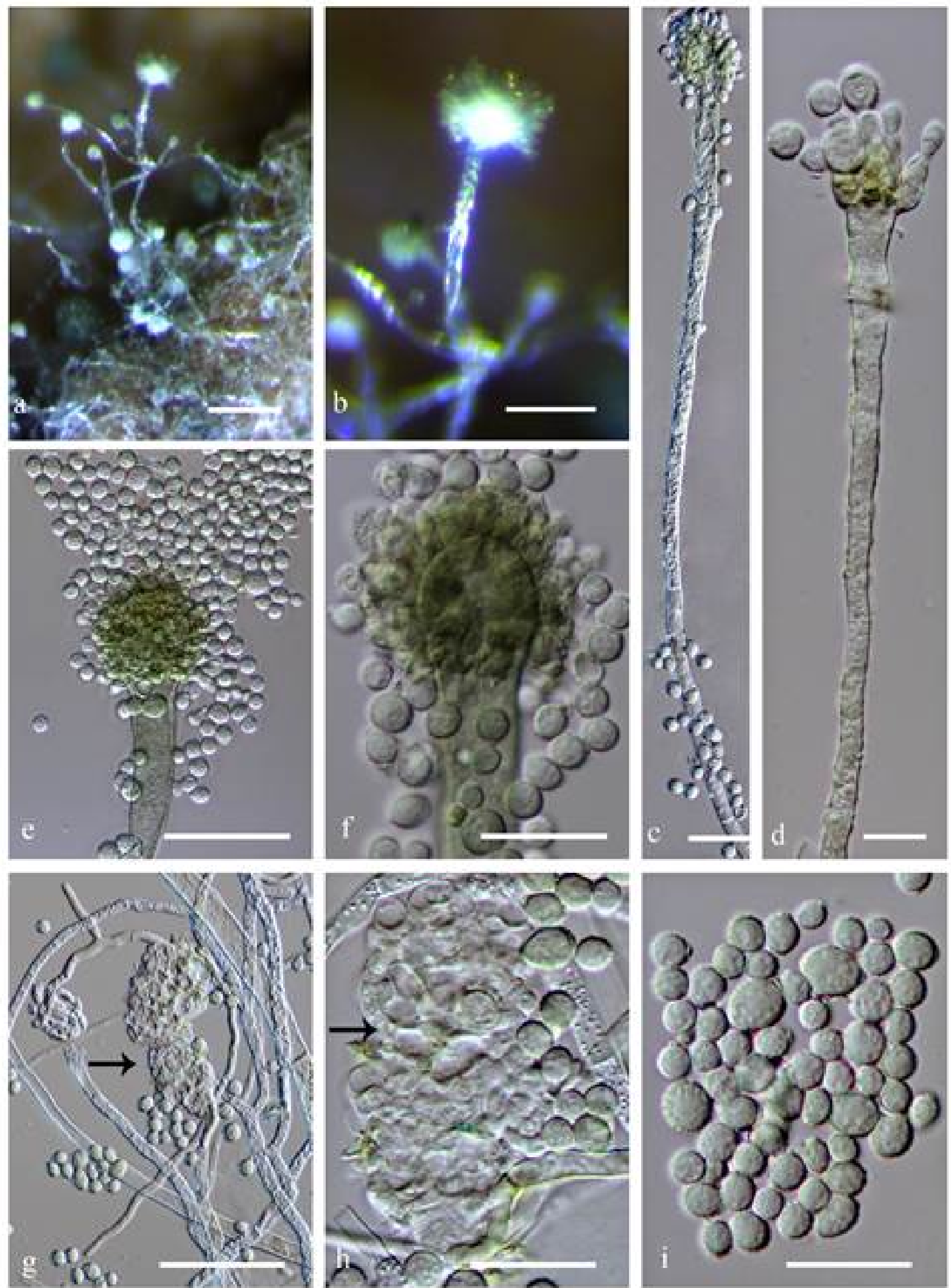

Fig. 3 - Aspergillus pseudoglaucus (MFLUCC 14-0336). a Synnemata on the Helvella sp. b Conidiophore. c-f Conidiophores with conidia. f Apex of conidiogenous cell. g, h Immature ascoma. i Conidia. Scale bars: $\mathrm{a}=1000 \mu \mathrm{m}, \mathrm{b}=100 \mu \mathrm{m} \mathrm{c}=25 \mu \mathrm{m} . \mathrm{d}=10 \mu \mathrm{m} \mathrm{e}, \mathrm{g}=50 \mu \mathrm{m}, \mathrm{f}, \mathrm{h}, \mathrm{i}$ $=20 \mu \mathrm{m}$. 

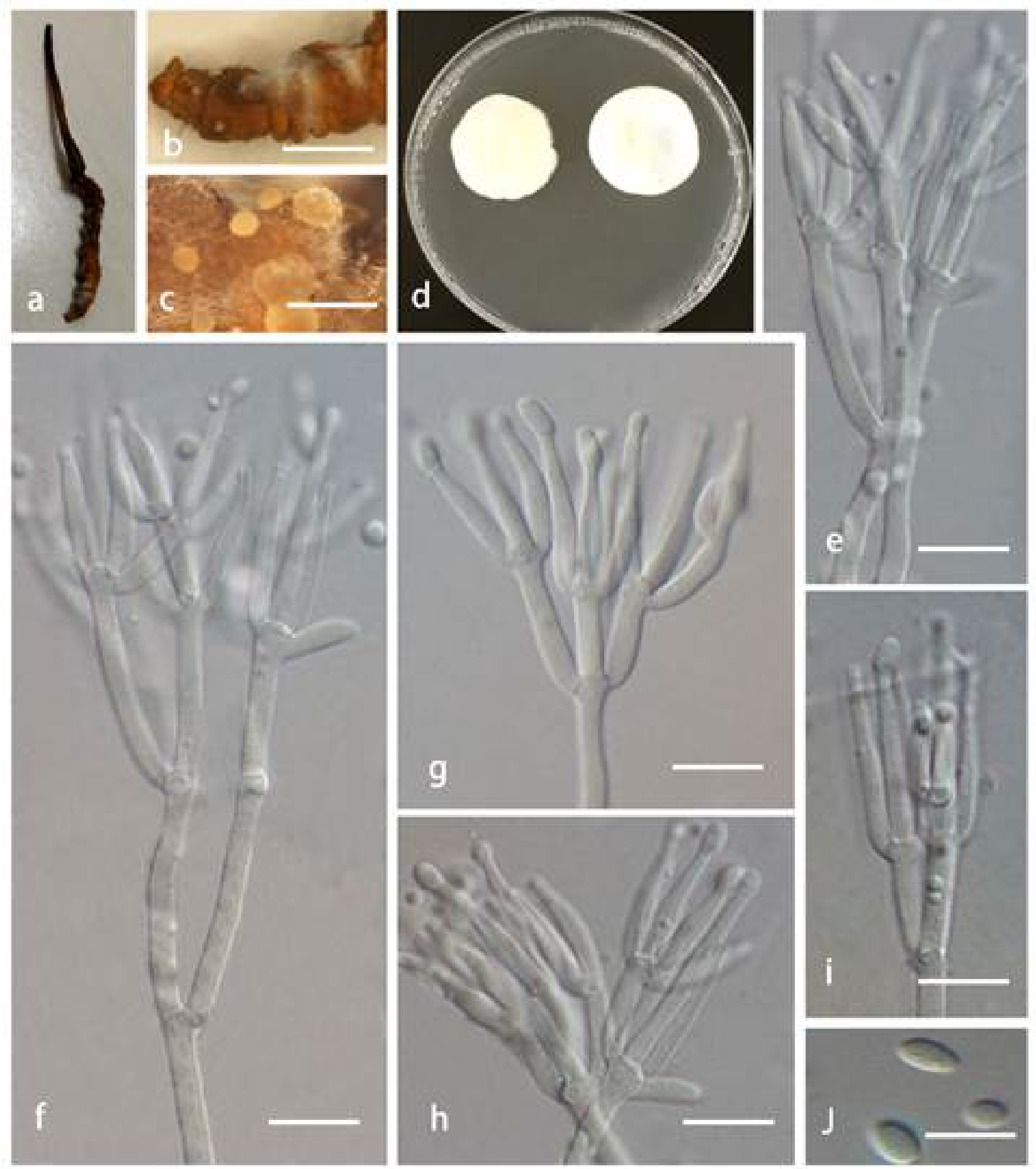

Fig. 4 - Cladobotryum protrusum (CGMCC 3.19064). a White colony on the fruiting body of Polyporaceae sp. b Conidiophores on the surface of mycelium. c-h Conidiophores. i-k Phialides. l-p Conidia. Scale bars: $\mathrm{a}=1 \mathrm{~mm}, \mathrm{~b}=200 \mu \mathrm{m}, \mathrm{c}=100 \mu \mathrm{m}, \mathrm{d}-\mathrm{h}=50 \mu \mathrm{m}, \mathrm{i}-\mathrm{p}=5 \mu \mathrm{m}$.

In this study, phylogenetic analysis based combined ITS and TUB sequences shows that our fungus clustered with all $C$. rosea $\mathrm{f}$. catenulata strains, together with the type strain with strong support (97\% BSML, 0.99 BYPP, Fig. S2). Therefore, we identify it as C. rosea f. catenulata. Clonostachys rosea f. catenulata are mainly isolated from soil and known as destructive mycoparasites (Schroers 2001, Krauss et al. 2013, Abreu et al. 2014). Its closed relative taxon, Clonostachys rosea has been reported to be associated with O. sinensis (Dong et al. 2015). This study finds that $C$. rosea f. catenulata is also associated with $O$. sinensis. 
Fusarium solani (Mart.) Sacc., Micheli 2(7): 296 (1881).

Fig. 5

$\equiv$ Fusisporium solani Mart., Die Kartoffel-Epidemie der letzten Jahre oder die Stockfäule und Räude der Kartoffeln (Munich) 3: 25-30 (1842)

$\equiv$ Neocosmospora solani (Mart.) L. Lombard \& Crous, in Lombard, van der Merwe, Groenewald \& Crous, Stud. Mycol. 80: 228 (2015)

Facesoffungi number: FoF 01873

Description from Epitypified specimen, please see detail in Schroers (2001)

Fungicolous or saprophytic on the fruiting body of Morchella sp. Asexual morph: Mycelium white, cottony to arachnoid. Conidial fructifications developing as loosely floccose masses of white mycelium bearing robust conidiophores with white spore masses. Conidiophores hyaline, septate, branched or unbranched, smooth-walled. Conidiophores consisting of single phialides, Phialides hyaline, cylindrical, wedge-shaped or allantoid, 9-16 $\times 2-4 \mu \mathrm{m}(\bar{x}=12 \times 3.2 \mu \mathrm{m}, \mathrm{n}=20)$. Conidia forming abundantly in the aerial mycelium from elongated lateral phialides, hyaline, cylindrical, wedge-shaped or allantoid, 1-3-septate 10-16 × 2-4 $\mu \mathrm{m}(\bar{x}=14 \times 3.1 \mu \mathrm{m}, \mathrm{n}=30)$. Sexual morph: Undetermined.

Material examined - CHINA, Gui Zhou Province, Guiyang city, on a fruiting body of Morchella sp. 8 April 2016; Xiao Y. P. (HMAS 279803) GenBank no. (ITS: MH459150, and TEF: MH464777, and RPB2: MH464783).

Notes - Fusarium solani species complex consists of a number of cryptic species due to the limitation of the morphological identification. Phylogenetic analyses based on multi-gene of ITS, TEF and RPB2 have revealed several new species in the Fusarium solani complex (O'Donnell 2000, Schroers et al. 2016). Our fungus produces falciform or fusiform conidia (Fig. 5), and the ITS sequence indicates it belongs to the Fusarium solani species complex. In this study, our isolate groups with strains of Fusarium solani with strong support (93\% BSML, 1.00 BYPP, Fig. S3). Therefore, the taxon is regarded as F. solani. Fusarium solani is a plurivorous plant pathogen, endophyte, decomposer, and as an opportunistic pathogen of humans and nutritional symbiont of insects (Schroers et al. 2016, Ilic et al. 2017). Herein, it is reported as a fungicolous taxon colonizing the fruiting body of Morchella sp. in China.

Hypomyces aurantius (Pers.) Tul., Annales des Sciences Naturelles Botanique 13: 12 (1860)

三Sphaeria aurantia Pers., Icon. Desc. Fung. Min. Cognit. (Leipzig) 2: 45 (1800)

Fig. 6

Facesoffungi number: FoF 06013

Description from Epitypified specimen, please see detail in Rogerson \& Samuels (1993)

Fungicolous, colonized on the fruiting body of Panellus sp. Asexual morph: Conidial fructifications developing as loosely floccose masses of white mycelium bearing robust conidiophores with white or yellowish spore masses. Conidiophores hyaline, septate, 40-90 × 2-3 $\mu \mathrm{m}(\bar{x}=7 \times 2.6 \mu \mathrm{m}, \mathrm{n}=10)$, attenuating to $1.0-2.0 \mu \mathrm{m}(\bar{x}=1.5, \mathrm{n}=10)$. Phialides hyaline, solitary or ralely in $2-5$ verticills, $15-25 \times 2-3 \mu \mathrm{m}(\bar{x}=18 \times 2.5 \mu \mathrm{m}, \mathrm{n}=20)$. Conidia hyaline, broadly ellipsoid, aspetate, $6-8 \times 3-5 \mu \mathrm{m}(\bar{x}=6.5 \times 4 \mu \mathrm{m}, \mathrm{n}=30)$. Sexual morph: Undetermined.

Material examined - CHINA, Guang Xi Province, Wuming Country, Daming Mountain on a fruiting body of Panellus sp. 14 April 2016; Dong C. H. (HMAS 279804) GenBank no. (LSU: MH459169, ITS: MH459151, TEF: MH464782 and RPB2: MH464786).

Notes - Hypomyces aurantius was introduced as a new species by Põldmaa (2011). The sexual morph is orange-colored (Põldmaa 2011). Its asexual stage is previously named Cladobotryum varium (Põldmaa 2011, Rossman et al. 2013). Our fungus produces the Cladobotryum-like conidiophores and conidia (Fig. 6), which resemble $H$. aurantius; and the ITS sequence indicates it belongs to $H$. aurantius. Phylogenetic analysis also shows our taxon groups with the type strain of $H$. aurantius with strong support (97\% BSML/1.00 BYPP, Fig. 1). Combination of the phylogenetic and morphological evidence, our collection also represents $H$. aurantius. Hypomyces aurantius is reported as the causing-agent of cobweb disease of cultivated 
mushrooms (Rossman et al. 2013). To our knowledge, it is a new record of mycoparasite of Panellus sp. in China.
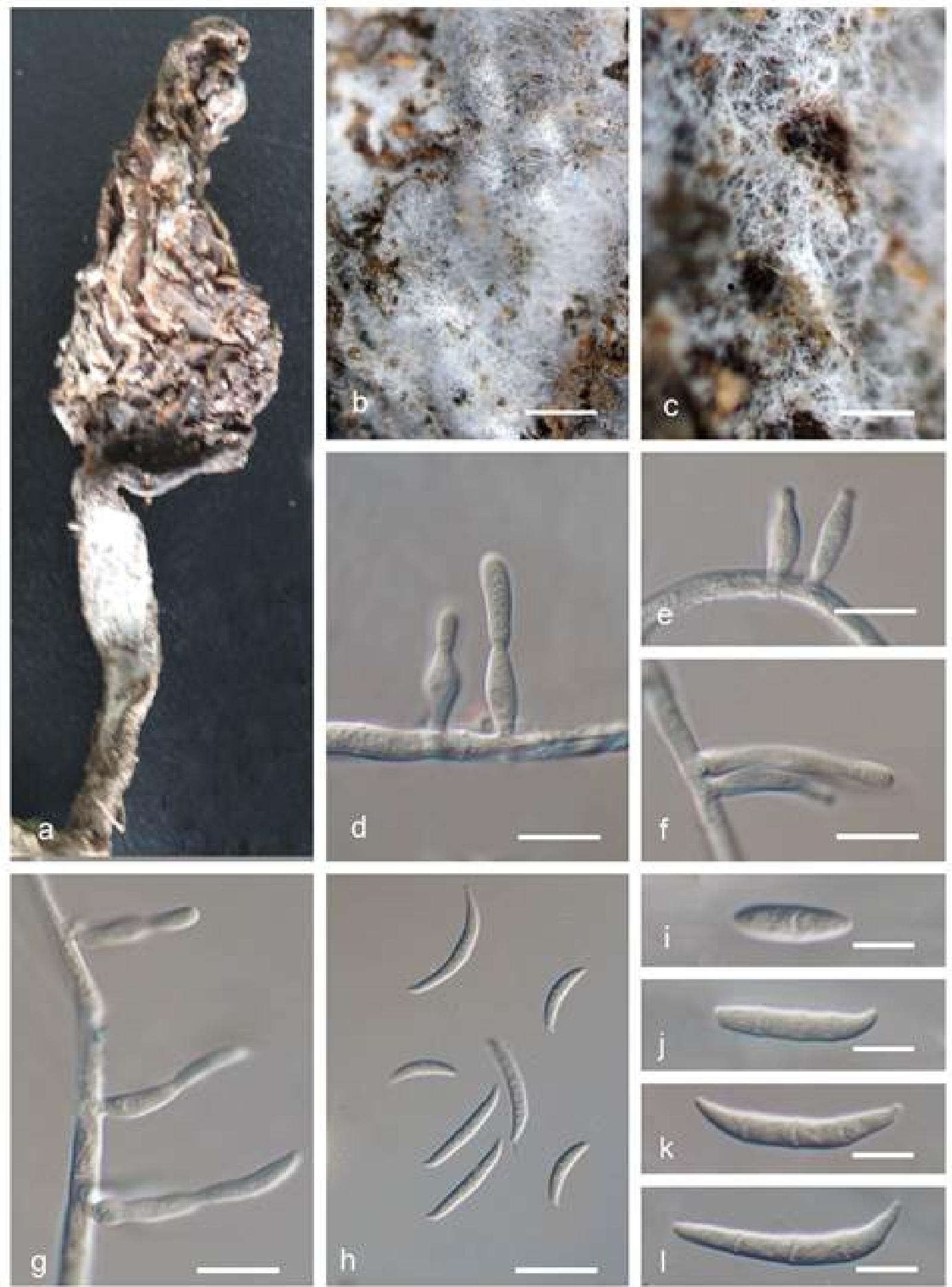

Fig. 5 - Fusarium solani (HMAS 279803). a Host fungi Morchella importuna. b, c Colony on Morchella sp. d-g Conidiogenous cells. $\mathrm{h}-\mathrm{l}$ Conidia. Scale bars: $\mathrm{a}=0.5 \mathrm{~cm}, \mathrm{c}=500 \mu \mathrm{m}, \mathrm{d}=100$ $\mu \mathrm{m}, \mathrm{e}-\mathrm{g}=10 \mu \mathrm{m}, \mathrm{h}=20 \mu \mathrm{m}, \mathrm{i}-\mathrm{l}=5 \mu \mathrm{m}$. 

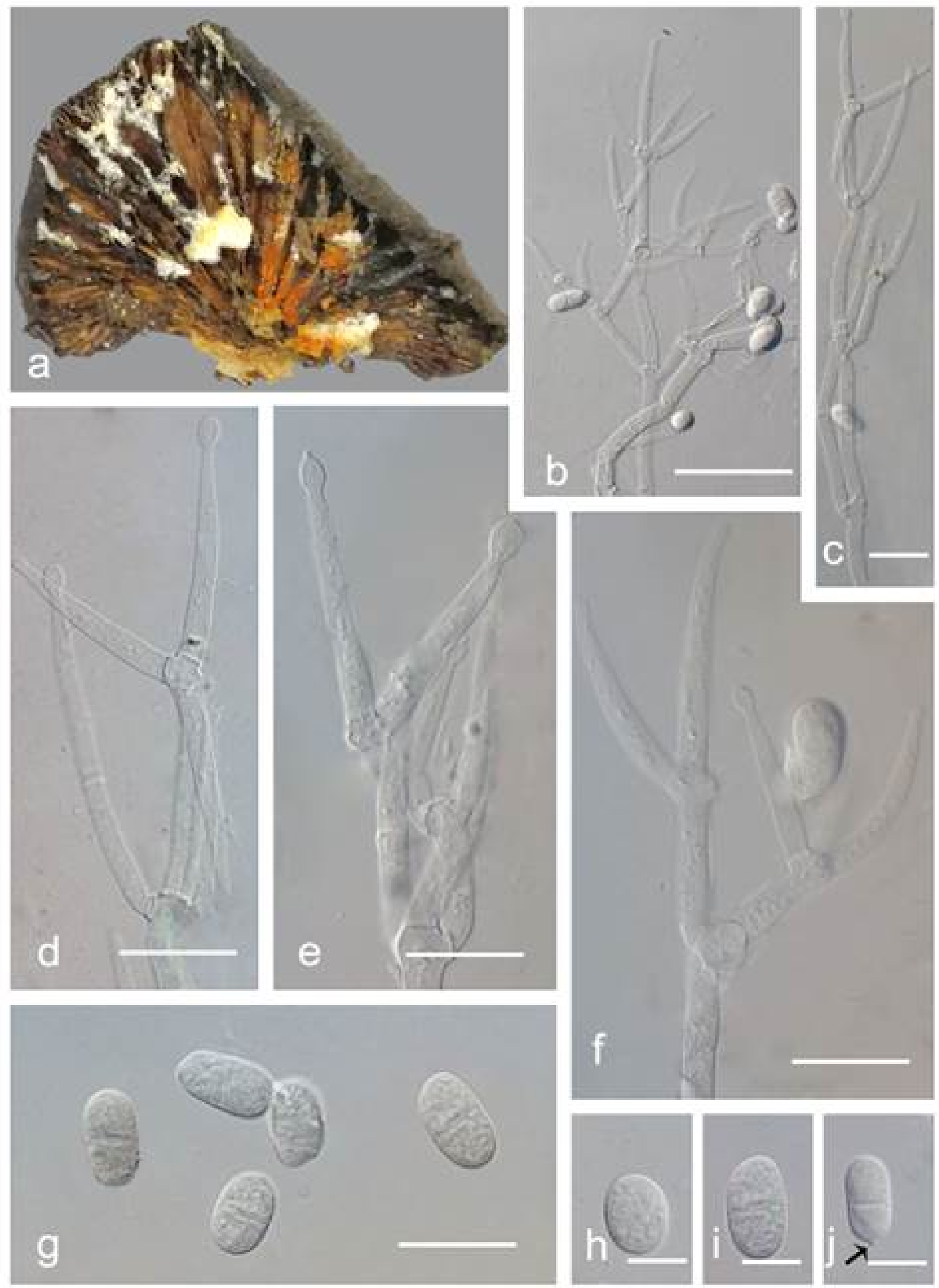

Fig. 6 - Hypomyces aurantius (HMAS 279804). a White, yellowish colony on the fruiting body of Panellus sp. b, c Conidiophores. $\mathrm{d}-\mathrm{f}$ Conidiogenous cells. g-j Conidia. J Hilum. Scale bars: $\mathrm{b}=50$ $\mu \mathrm{m}, \mathrm{c}=25 \mu \mathrm{m}, \mathrm{d}-\mathrm{g}=10 \mu \mathrm{m}, \mathrm{h}-\mathrm{j}=5 \mu \mathrm{m}$. 
Facesoffungi number: FoF 06014

Description from the type specimen, please see detail in Rogerson \& Samuels (1989)

Fungicolous, colonized on the fruiting body of Boletus sp. Asexual morph: Conidial fructifications developing as loosely floccose masses of white mycelium bearing robust conidiophores with white or yellowish spore masses. Conidiophores hyaline, septate, phialides solitary or ralely in verticills, $120-260 \times 2-3 \mu \mathrm{m}(\bar{x}=7 \times 6 \mu \mathrm{m}, \mathrm{n}=10)$, attenuating to $1.0-2.0 \mu \mathrm{m}$ $(\bar{x}=1.5 \mu \mathrm{m}, \mathrm{n}=10)$. Phialoconida hyaline, ellipsoid, 6-12 $\times 4-7 \mu \mathrm{m}(\bar{x}=7 \times 6 \mu \mathrm{m}, \mathrm{n}=30)$. Aleurioconidia yellow, subglobose to globose, with irregular furrows, $25-30 \mu \mathrm{m}(\bar{x}=27 \mu \mathrm{m}, \mathrm{n}=$ 30). Sexual morph: Undetermined.

Material examined - CHINA, Chiang Rai Province, on a fruiting body of Boletaceae sp. Mae Salong Mountain, 22 July 2016; Sun J. Z. (MFLU17-1391), living culture CGMCC 3.19062. GenBank no. (LSU: MH459168, ITS: MH459152, and RPB2: MH464785).

Notes -The asexual-state of Hypomyces boletiphagus is previously named Sepedonium boletiphagum, which characterized by furrowed, globose aleurioconidia (Sahr et al. 1999). Members of Sepedonium are usually constrained to the host Boletales (Rogerson \& Samuels 1989, Sahr et al. 1999). Several species have been connected with Hypomyces (Sahr et al. 1999). Our collection produces Sepedonium-like yellow globose aleurioconidia on the fruiting body of Boletus sp. (Fig. 7), which is similar to H. boletiphagus. In the phylogenetic tree, it groups with the type strain of Hypomyces boletiphagus strongly supported by bootstrap support value, Fig. 1). Therefore, it is identified as $H$. boletiphagus. Hypomyces boletiphagus has been found on Austroboletus gracilis and Pulveroboletus ravenelii in the USA, Gyroporus castaneus in New Zealand (Rogerson \& Samuels 1989). To our knowledge, it is a new record in Thailand.

Hypomyces boletus Jing Z. Sun, Xing Z. Liu \& K.D. Hyde sp. nov.

Fig. 8

MycoBank number: MB827516; Facesoffungi number: FOF 06029

Etymology - The epithet boletus refers to the generic name of host fungus.

Fungicolous, growing on a fruiting body of Boletus sp. Sexual morph: Undetermined. Asexual morph: Hyphomycetous. Mycelium partly superficial, developing as floccose masses of septate, branched, smooth and hyaline hyphae bearing robust conidiophores with white spore masses. Conidiophores hyaline, erect, flexuous, septate, smooth. With two types of conidiogenous cells phialidic and aleuriogenic. Type A: Phialides solitary or rarely in verticels, 40-90 × 2-3 $\mu \mathrm{m}$ $(\bar{x}=58 \times 2.5 \mu \mathrm{m}, \mathrm{n}=30)$, attenuating to $1.0-2.0 \mu \mathrm{m}$ at their apices. Phialoconida acrogenous, hyaline, broadly fusiform, 1-spetate when mature, $6-10 \times 3-4 \mu \mathrm{m}(\bar{x}=7.5 \times 3.5 \mu \mathrm{m}, \mathrm{n}=50)$. Type B: Aleuriogenic discrete, on short side branches. Aleurioconidia hyaline, globose to gourd shaped, 1-septate, constricted at septum, with upper bigger and lower smaller cells, with angular tubercles on surface, $10-15 \mu \mathrm{m}(\bar{x}=13 \mu \mathrm{m}, \mathrm{n}=50)$ in diam.

Material examined - THAILAND, Chiang Rai Province, Mae Fah Luang, on the fruiting body of Boletus sp. 26 July 2016; Sun J. Z. (MFLU 17-1392 holotype; HMAS 279934, isotype), ex-type living culture CGMCC 3.19063, living culture CGMCC 3.19581. GenBank no. LSU: MH459170, ITS: MH459153, and RPB2: MH464787.

Note - Phylogenetically, our taxa groups with Hypomyces species with Sepedonium asexual morph, and shows an affinity to Hypomyces chrysospermus, Sepedonium laevigatum, and Sepedonium tulasneanum but with weak support (Fig. 1). These fungi usually occur on the fruiting body of Boletales (Rogerson \& Samuels 1989, Sahr et al 1999). Hypomyces chrysospermusis and S. laevigatum are characterized by producing yellowish globose aleurioconidia but $S$. laevigatum with slightly shorter tubercles. Sepedonium tulasneanum is characterized by producing spindle-shaped to lemon-shaped aleurioconidia (Sahr et al 1999). Hypomyces boletus can be distinguished from these taxa by the production of hyaline gourd-shaped aleurioconidia. Our fungus, besides the fusiform, 1septate phialoconidia, produces Mycogone-like aleurioconidia on the fruiting body of Boletus sp. (Fig. 8). Phylogenetically, it groups with Hypomyces species with Sepedonium asexual morph, and has an affinity to $H$. chrysospermus, S. laevigatum, and S. tulasneanum but with weak support (Fig. 
1). Hypomyces boletus can be distinguished from these taxa by the production of hyaline gourdshaped aleurioconidia on a fruiting body of Boletus sp. Therefore, herein $\mathrm{H}$. boletus is introduced as a novel taxon.
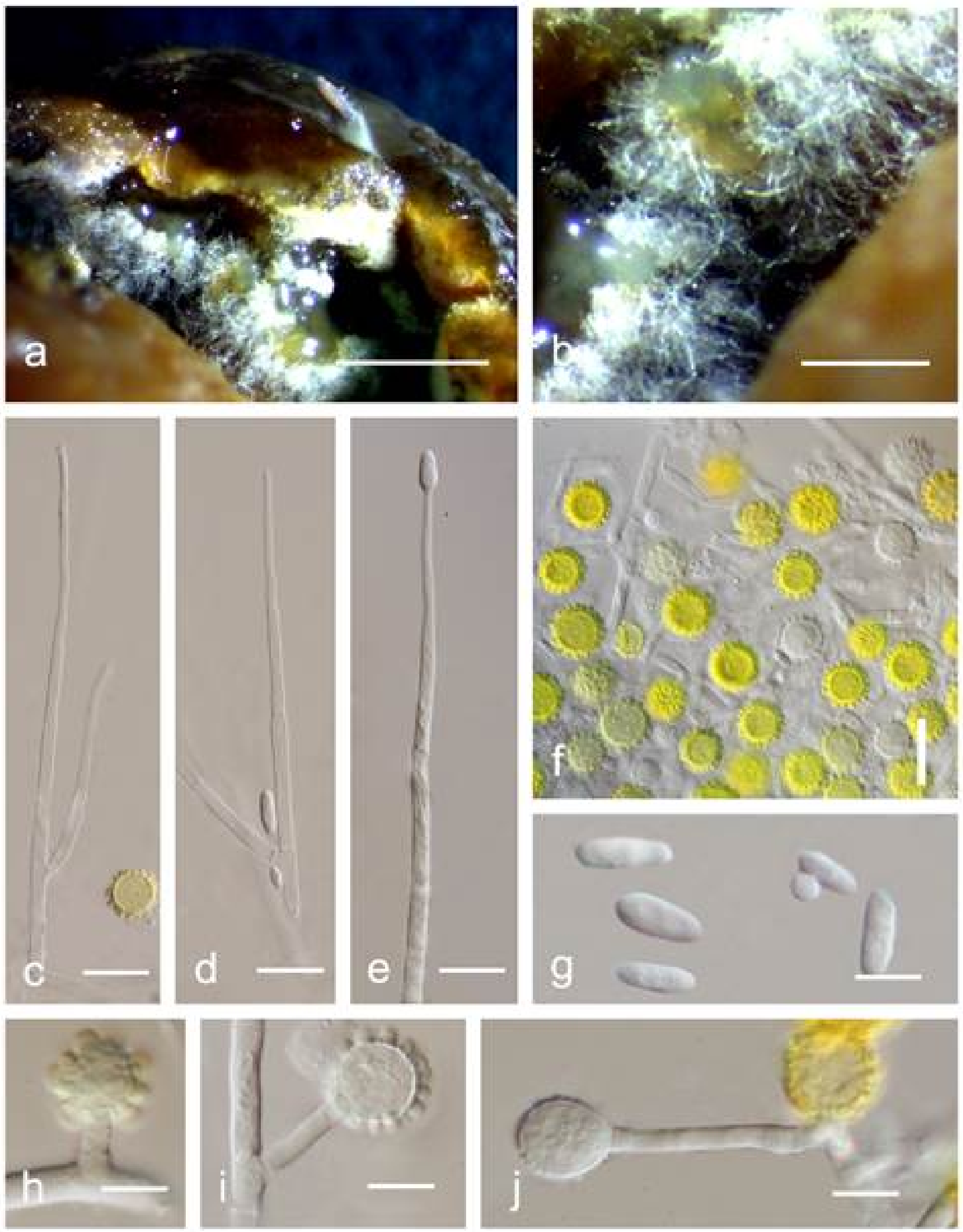

Fig. 7 - Hypomyces boletiphagus (MFLU 17-1391). a, b White colony on the fruiting body of Boletus sp. $\mathrm{c}-\mathrm{e}, \mathrm{h}-\mathrm{j}$ Conidiogenous cells. $\mathrm{f}$ Aleurioconidia. g Conidia. Scale bars: $\mathrm{a}=2 \mathrm{~mm}, \mathrm{~b}=$ $500 \mu \mathrm{m}, \mathrm{c}-\mathrm{g}=40 \mu \mathrm{m}, \mathrm{h}-\mathrm{j}=20 \mu \mathrm{m}$. 

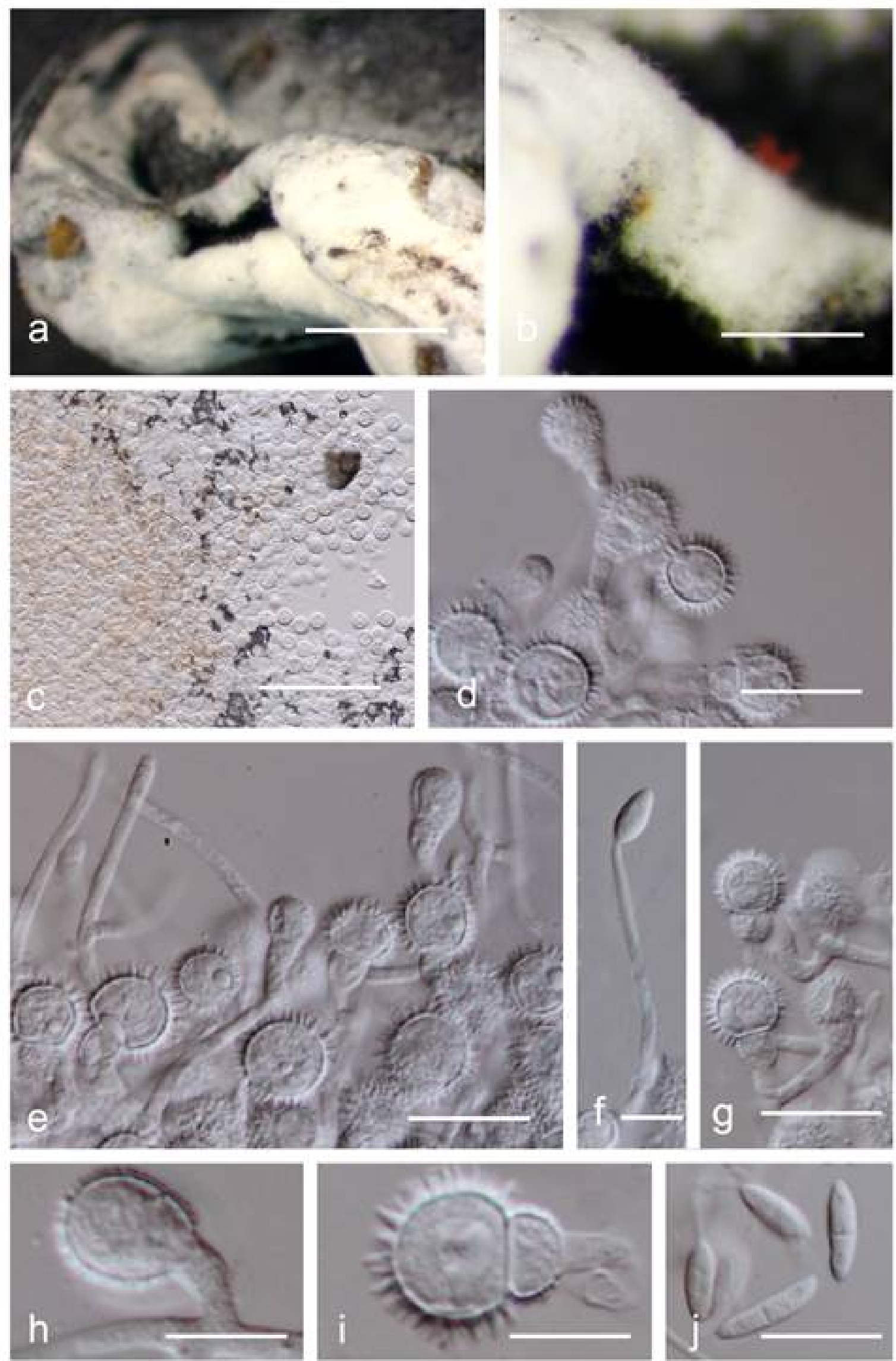

Fig. 8 - Hypomyces boletiphagus (MFLU 17-1392). a, b White colony on the fruiting body of Boletus sp. d-h Conidiogenous cells. c, i Aleurioconidia. j Conidia. Scale bars: $\mathrm{a}=2 \mathrm{~mm}, \mathrm{~b}=500$ $\mu \mathrm{m}, \mathrm{c}=100 \mu \mathrm{m}, \mathrm{d}, \mathrm{e}, \mathrm{g}=20 \mu \mathrm{m}), \mathrm{f}, \mathrm{h}-\mathrm{j}=10 \mu \mathrm{m}$. 
MycoBank number: MB827517; Facesoffungi number: FOF 06030

Etymology - The epithet fistulina refers to generic of host fungus.

Fungicolous, growing on the fruiting body of Fistulina sp. Asexual morph: Hyphomycetous. Mycelium partly superficial, composed of septate, loosely branched, floccose masses of white, hyaline hyphae bearing conidiophores and white spore masses. Conidiophores macronematous, mononematous, erect, septate, branched, with branches arranged in 1-3 verticillate whorls, hyaline, 200-300 × 4-6 $\mu \mathrm{m}(\bar{x}=280 \times 5.5 \mu \mathrm{m}, \mathrm{n}=10)$. Phialides verticillate, determinate, terminal, 30-60 $\times 4-6 \mu \mathrm{m}(\bar{x}=42 \times 5.5 \mu \mathrm{m}, \mathrm{n}=50)$, attenuating to $1.0-2.0 \mu \mathrm{m}$ at their apices, slightly tapering at the tip. Conidia acrogenous, holoblastic, broadly ellipsoidal, each with a broad, blunt basal apiculus and broadly rounded apex, 1-3-septate when mature, slightly constricted at the septa, thin-walled, smooth-walled, hyaline, 16-32 ×6-10 $\mu \mathrm{m}(\bar{x}=27 \times 8 \mu \mathrm{m}, \mathrm{n}=50)$. Sexual morph: Undetermined.

Material examined - CHINA, Guang Xi Province., Li An City, Da Ming Mountain, on the fruiting body of Fistulina sp. 15 April 2017; Dong C. H. (HMAS 279800, holotype; MFLU 181392, isotype), ex-type living culture CGMCC 3.19582, living culture CGMCC 3.19583. GenBank no. (LSU: MH459171, ITS: MH459154, and TEF: MH464781).

Note - Hypomyces fistulina produces the Cladobotryum-like or Trichothecium-like conidiophores and conidia (Fig. 9). Phylogenetically, our taxa group with Hypomyces species with Cladobotryum asexual morph, and shows an affinity to Cladobotryum croceum, Cladobotryum gracile, Hypomyces aurantius, and Hypomyces siamensis but with weak support. Hypomyces fistulina has relatively larger conidia $(16-32 \times 6-10 \mu \mathrm{m})$ than that of C. croceum $(12-20 \times 4-5.5$

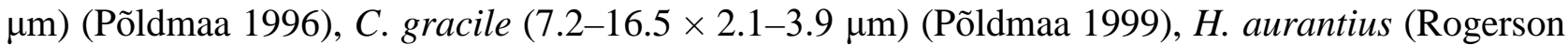
\& Samuels 1993) and H. siamensis (6.5-21.7 × 3.1-6.2 $\mu \mathrm{m})$ (Põldmaa \& Samuels 2004). In addition, the conidia of $H$. fistulina have 1-3-septate against C. croceum, $H$. aurantius, and $H$. siamensis with 0-1-septate (Põldmaa 1996, 1999, Põldmaa \& Samuels 2004). Therefore, our collections are considered representing a novel taxon.

Hypomyces rosellus (Alb. \& Schwein.) Tul. \& C. Tul., Annales des Sciences Naturelles Botanique 13:12 (1860)

Fig. 10

Facesoffungi number: FoF 06015

Fungicolous on the fruiting body of Agaricus bisporus. Asexual morph: Conidial fructifications developing as loosely floccose masses of white mycelium bearing robust conidiophores with white spore masses. Conidiophores hyaline, erect, with branches arranged in verticillate whorls, in pairs, and singly, bearing conidia acrogenously on the primary branches or on secondary branches. Phialides hyaline, 30-40 × 3-4.5 $\mu \mathrm{m}(\bar{x}=36 \times 4.2 \mu \mathrm{m}, \mathrm{n}=20)$ wide basally, and tapering slightly to the tip. Conidia approximately, colorless, broadly ellipsoidal, each having a broad, blunt basal apiculus and appearing broadly rounded at the apex, 3-septate when mature, commonly somewhat constricted at the septa, thin-walled, smooth-walled, 26-33 $\times 10-13 \mu \mathrm{m}(\bar{x}=$ $11.5 \times 4.2 \mu \mathrm{m}, \mathrm{n}=30$ ). Sexual morph: Undetermined.

Material examined - CHINA, Gan Su Province, on a fruiting body of Agaricus bisporus. 26 July 2016, Liu X. Z. (HMAS 279799), living culture CGMCC 3.19065. GenBank no. (LSU: MH459172, ITS: MH459155, TEF: MH464780 and RPB2: MH464788)

Notes - Hypomyces rosellus is more commonly known in the mushroom industry by its synonym, Dactylium dendroides, or as its asexual stage of Cladobotryum dendroides. Our taxon produces Cladobotryum-like conidiophores and conidia (Fig. 10), which is similar to Hypomyces rosellus. In this study, our isolate groups with a strain of Hypomyces rosellus with strong support (Fig. 1). Therefore, the taxon is named $H$. rosellus. Hypomyces rosellus is more commonly known in the mushroom industry by its synonym, Dactylium dendroides, or as its asexual stage of Cladobotryum dendroides. It is responsible for the cobweb disease of Agaricus bisporus (Tamm \& Põldmaa 2013). To our knowledge, it is a new fungal record causing cobweb disease of $A$. bisporus in Gansu Province, China. 
Cladobotryum protrusum K. Põldmaa, Studies in Mycology 68: 22 (2011)

Fig. 11

Facesoffungi number: FoF 06011

Description from the type specimen, please see detail in (Põldmaa 2011)

Fungicolous on the fruiting body of decayed Basidiomycetes. Asexual morph: Conidial fructifications developing as loosely floccose masses of white mycelium bearing robust conidiophores with yellowish spore masses. Conidiophores erect, with branches arranged in verticillate whorls, with 3-5 verticils, $2-4$ branches producing conidiogenous cells formed from one point, sometimes in lateral position in a verticil of Phialides. Phialides colorless, $20-45 \times 3.5-$ $5.0(\bar{x}=42 \mu \mathrm{m}, \mathrm{n}=30)$, attenuating to $2.0-3.0 \mu \mathrm{m}(\bar{x}=2.4 \mu \mathrm{m}, \mathrm{n}=30)$. Conidia hyaline, ellipsoidal, sometimes cylindrical, long clavate or fusiform, with protuberant hilum, (0-)1-septate, slightly constricted at the septum, smooth-walled, 14-22 ×5-8 $\mu \mathrm{m}(\bar{x}=19 \times 6.5 \mu \mathrm{m}, \mathrm{n}=30)$. Sexual morph: Undetermined.
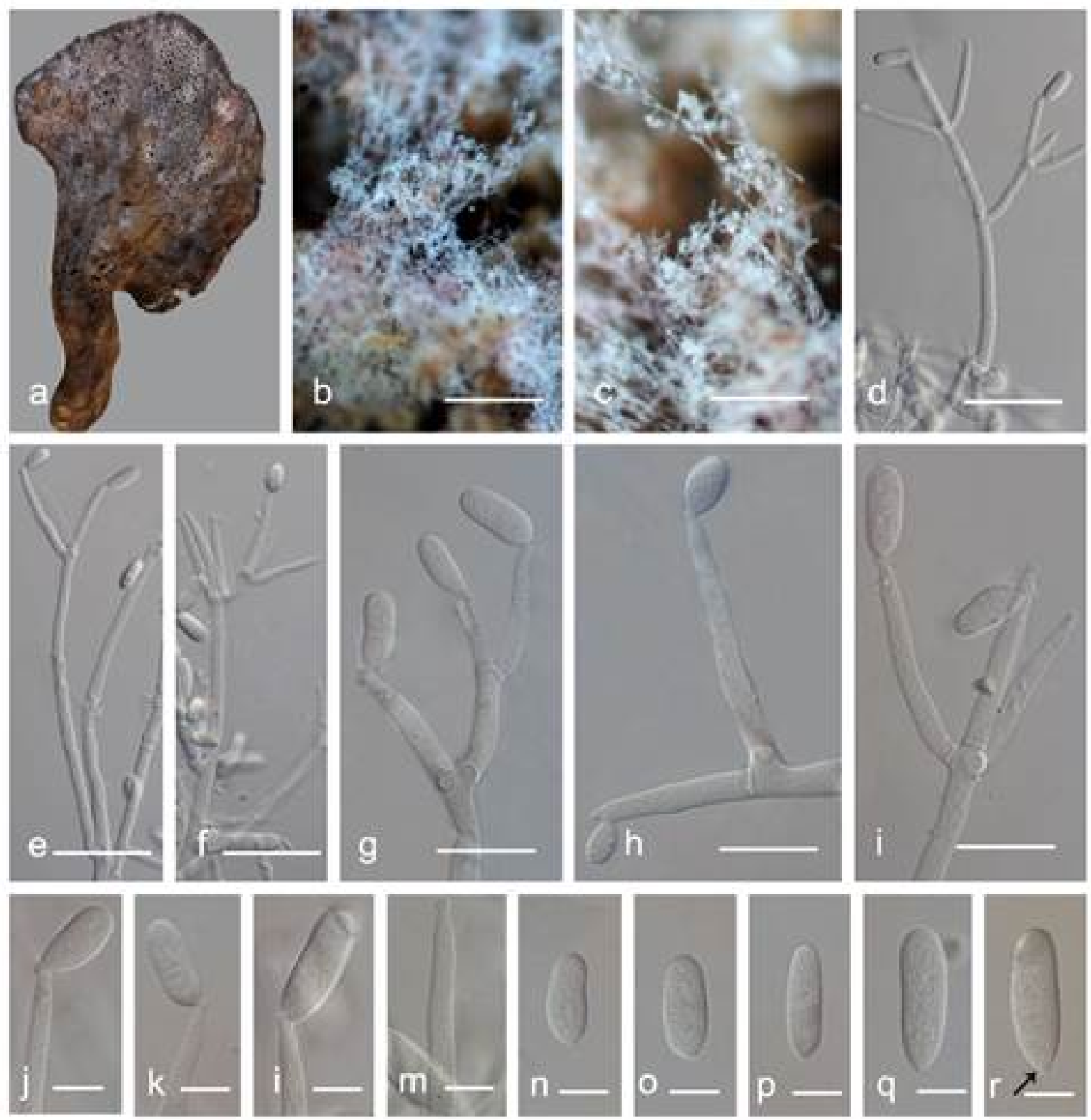

Fig. 9 - Hypomyces boletiphagus (holotype HMAS 279800). a, b White colony on the fruiting body of Fistulina sp. b, c Mycelia on the surface of Fistulina sp. d-f Conidiophores. g-m Conidiogenous cells with conidia. n-r. Conidia. $r$ Hilum. Scale bars: $b, c=200 \mu m, d-f=50$ $\mu \mathrm{m}, \mathrm{g}-\mathrm{i}=20 \mu \mathrm{m}, \mathrm{j}-\mathrm{r}=10 \mu \mathrm{m}$. 

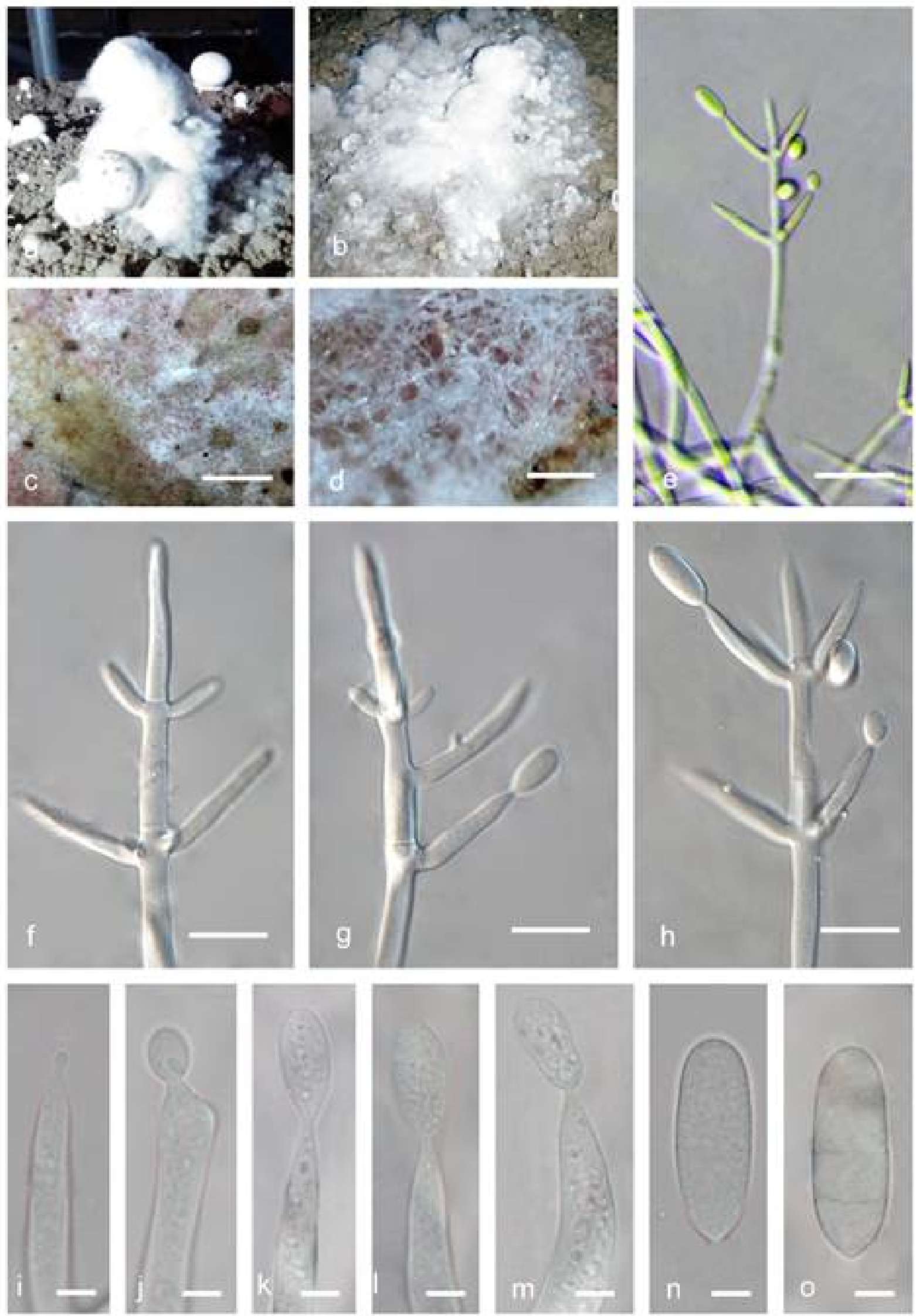

Fig. 10 - Hypomyces rosellus (MFLU 17-1392). a, b White colony on the fruiting body of Agaricus bisporus. c, d Mycelia on the surface of Agaricus bisporus. e-h Conidiophores and conidiogenous cells. $\mathrm{i}-\mathrm{m}$ Conidiogenous cells with conidia. $\mathrm{n}$, o Conidia. Scale bars: $\mathrm{c}=1 \mathrm{~mm}, \mathrm{~d}=200 \mu \mathrm{m}, \mathrm{e}=50$ $\mu \mathrm{m}, \mathrm{f}-\mathrm{h}=25 \mu \mathrm{m}, \mathrm{i}-\mathrm{O}=5 \mu \mathrm{m}$. 

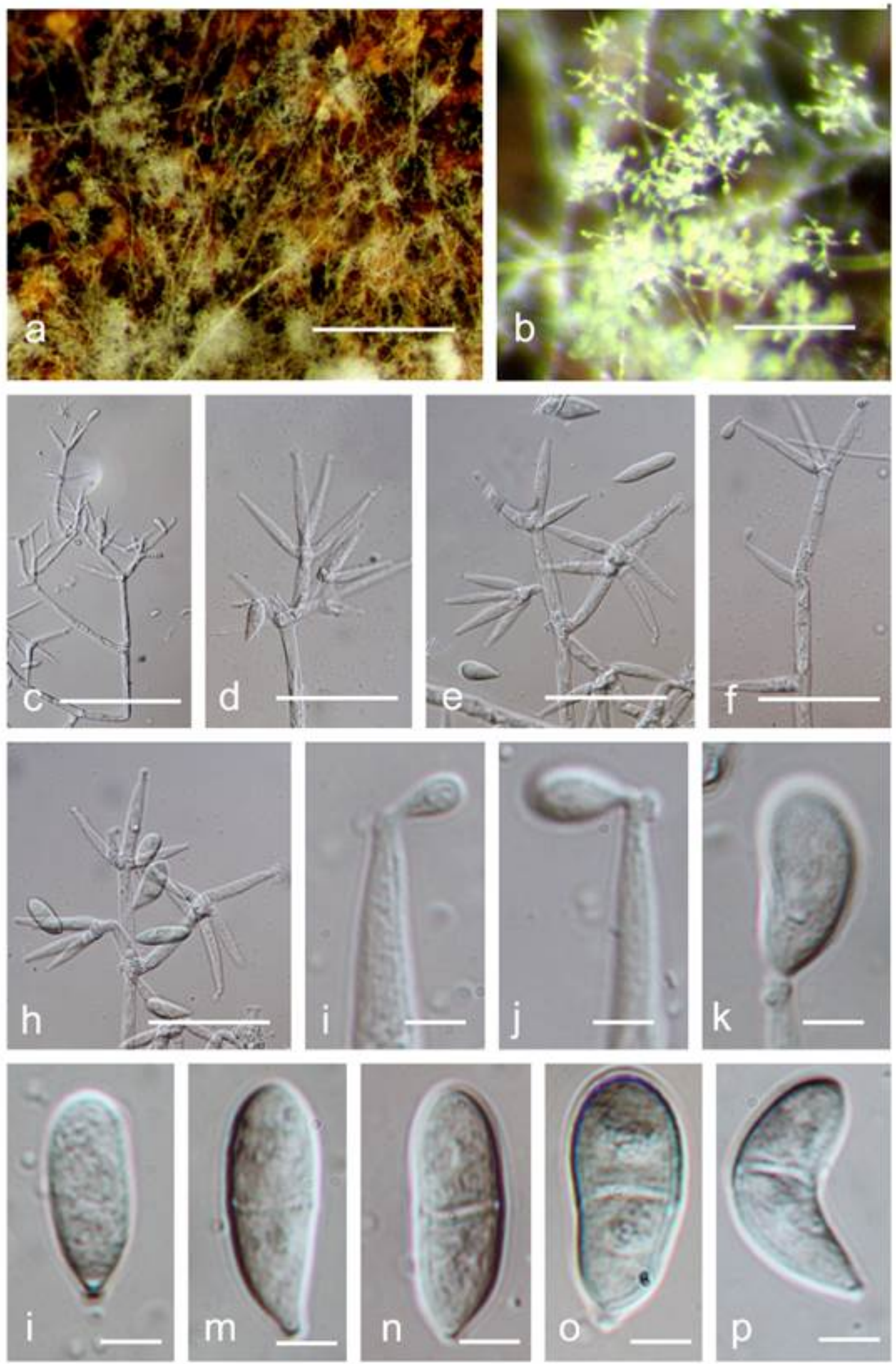

Fig. 11 - Cladobotryum protrusum (CGMCC 3.19064). a White colony on the fruiting body of Polyporaceae sp. b Conidiophores on the surface of mycelium. c-h Conidiophores. i-k Phialides. l-p Conidia. Scale bars: $\mathrm{a}=1 \mathrm{~mm}, \mathrm{~b}=200 \mu \mathrm{m}, \mathrm{c}=100 \mu \mathrm{m}, \mathrm{d}-\mathrm{h}=50 \mu \mathrm{m}, \mathrm{i}-\mathrm{p}=5 \mu \mathrm{m}$. 
Material examined - THAILAND, Chiang Rai Province, Mae Fah Luang, on a decayed mushroom. 26 July 2016; Sun J. Z. living CGMCC 3.19064. GenBank no. (LSU: MH459167, ITS: MH459156, and RPB2: MH464784)

Notes - Cladobotryum protrusum differs from other Hypmyces by the tree-like conidiophores, profusely branched at the apex, protrusions formed at conidiogenous elongations that are often transversely placed at the apices of conidiogenous cells, and formation of greenish conidia (Põldmaa 2011). Our fungus produces the Cladobotryum-like conidiophores and 1-sepate conidia (Fig. 11), which resembles $C$. Protrusum; and the ITS sequence indicates it belongs to $C$. protrusum. In the multi-gene phylogeny, our collection also groups with the strains of $C$. protrusum including the type strain (Fig. 1). This evidence supports our fungus is identical to C. protrusum. Cladobotryum protrusum is a fungicolous fungus on Agaricales and Polyporales in tropical regions (Põldmaa 2011). To our knowledge, it is a new record in Thailand.

Lecanicillium fungicola var. aleophilum (W. Gams \& Zaayen) W. Gams \& Zare, Mycological Research 112 (7): 821 (2008)

Fig. 12

Facesoffungi number: FoF 06016

Fungicolous, colonies form brown spots on a fruiting body of Agaricus bisporus. Asexual morph: Conidiophores generally arising from submerged hyphae, hyaline, erect, up to over $400 \mu \mathrm{m}$ long, about $2-3 \mu \mathrm{m}$ wide at the base, thick-walled, bearing many whorls of $2-5$ phialides. Phialides 15-30 $\mu \mathrm{m}(\bar{x}=26 \mu \mathrm{m}, \mathrm{n}=30)$ long, from $1.5-2.5 \mu \mathrm{m}(\bar{x}=2 \mu \mathrm{m}, \mathrm{n}=30)$ gradually tapering to 0.8-1.2 $\mu \mathrm{m}(\bar{x}=1 \mu \mathrm{m}, \mathrm{n}=30)$. Conidia hyaline, forming mostly globose heads, oblong, fusiform, long ellipsoidal to almost cylindrical, with conically tapering and ultimately rounded tips, equal at both ends, usually straight, smooth-walled, 3.5-7 $\times 2-3 \mu \mathrm{m}(\bar{x}=4.5 \times 2.5 \mu \mathrm{m}, \mathrm{n}=30)$. Chlamydospores absent. Sexual morph: Undetermined.

Material examined - CHINA, Gan Su Province, Lan Zhou City on a fruiting body of Agaricus bisporus in a mushroom farm. 22 August 2016; Sun J. Z. (HMAS279801), living culture CGMCC 3.19067. GenBank no. (ITS: MH459157, and SSU: MH454345).

Notes - Lecanicillium fungicola var. aleophilum have been introduced as new combinations to accommodate the fungicolous fungus Verticillium fungicola var. aleophilum based on phylogenetic analysis of ITS and SSU sequences (Zare \& Gams 2008). Our isolate produces the Verticillium-like conidiophores and ovoid conidia (Fig. 12), which is similar to Lecanicillium fungicola; and the ITS sequence indicates it belongs to the Lecanicillium fungicola species complex. Besides the difference in thermal tolerance, phylogenetic analysis based on ITS and SSU sequences also performs well in distinguishing these two taxa (Zare \& Gams 2008). In this study, our isolate clusters with Lecanicillium fungicola var. aleophilum with strong support (100\% BSML/1.00 BYPP, Fig. S4). Therefore, our strain is identified as L. fungicola var. aleophilum. This fungus is one of dry bubble disease-causing agent of Agaricus bisporus (Zare \& Gams 2008). Herein, L. fungicola var. aleophilum is isolated from A. bisporus as well. It is a new record in Gansu Province, China.

Paecilomyces formosus (Sakag., May. Inoue \& Tada) Houbraken \& Samson, in Samson, Houbraken, Varga \& Frisvad, Persoonia 22: 21 (2009)

Fig. 13

Facesoffungi number: FoF 06017

Fungicolous on the fruiting body of Fistulina sp. Asexual morph: Mycelium mostly immersed in the substratum. Conidiophores hyaline, irregularly branched, with 2-5 verticils. Phialides monothetic, alternate, occurring directly on aerial hyphae, tapering gradually from the base to the tip, 15-30 × 1.5-2.5 $\mu \mathrm{m}(\bar{x}=20 \times 2 \mu \mathrm{m}, \mathrm{n}=20)$. Conidia hyaline, one-celled, smooth-walled, ovoid or oblong, 3.5-6.0 $\times 2-3 \mu \mathrm{m}(\bar{x}=4 \times 2.5 \mu \mathrm{m}, \mathrm{n}=20)$. Sexual morph: Undetermined.

Material examined - CHINA, Guang Xi Province, on a fruiting body of Fistulina sp. 15 April 2017; Dong C. H., living culture CGMCC 3.19066. GenBank no. (ITS: MH459158)

Notes - Our fungus produces the Paecilomyces-like conidiophores and ovoid conidia (Fig. 13). The ITS sequence indicates it belongs to the Paecilomyces formosus complex. Paecilomyces 
formosus complex consists of three taxa that could not be distinguished by microscopical examination. The single gene of ITS sequence could distinguish it from other species of Paecilomyces (Samson et al. 2009). In this study, phylogenetic analysis based on ITS sequence shows our collection groups all strains of $P$. formosus with strong support (100\% BSML, 1.00 BYPP, Fig. S5). Paecilomyces formosus has been isolated from soil, wood, sponge, human beings (bone marrow, blood), the air in a bedroom and rhizosphere of Senseviera trifasciata (Samson et al. 2009). Herein we report it as a fungicolous taxon on Fistulina sp. in China.
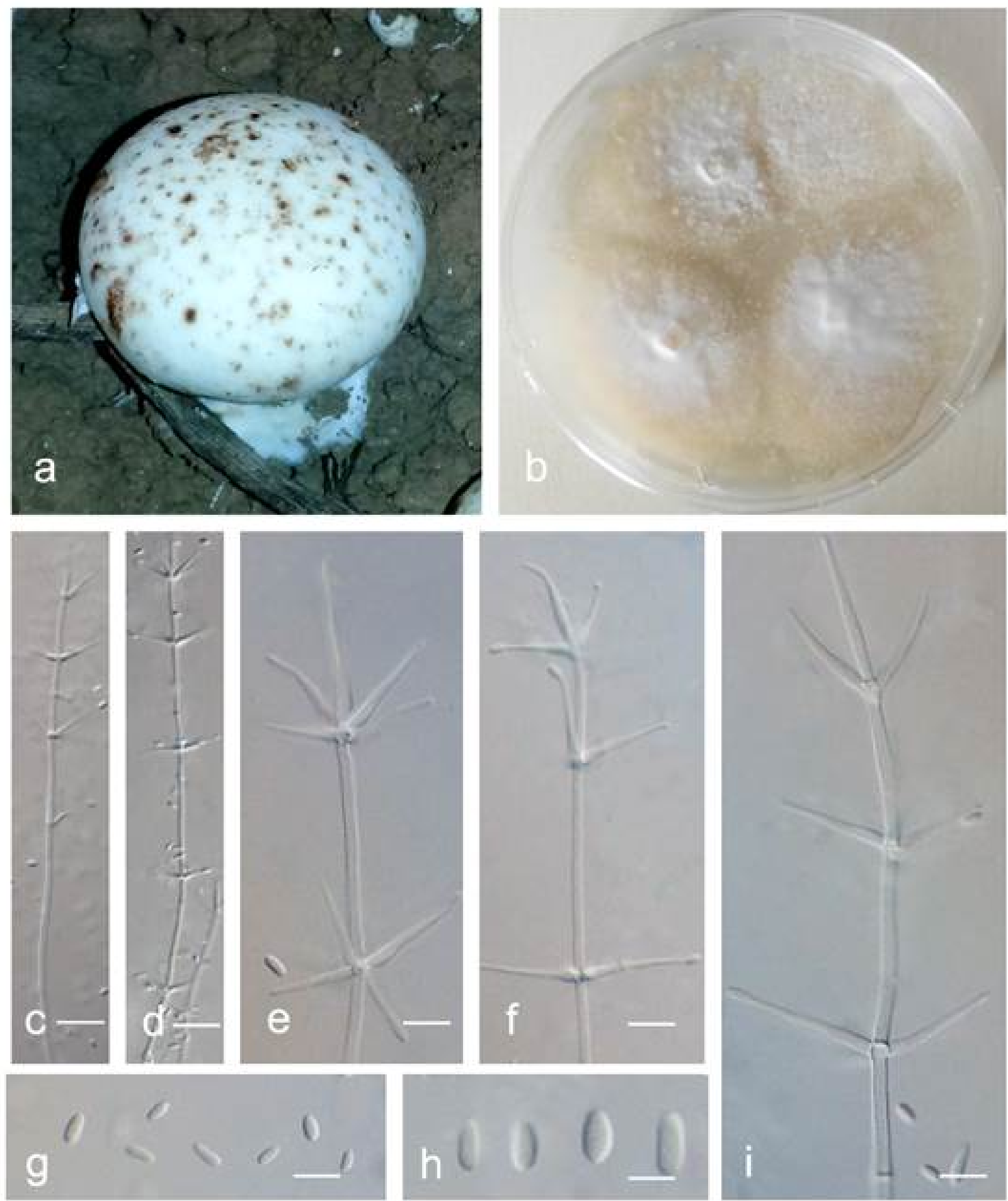

Fig. 12 - Lecanicillium fungicola var. aleophilum (CGMCC 3.19067). a Brown spots on the fruiting body of Agaricus bisporus. b Culture on PDA. c, d Conidiophores. e, f, i Phialides. g, h. Conidia. Scale bars: c, $\mathrm{d}=40 \mu \mathrm{m}), \mathrm{e}-\mathrm{g}=20 \mu \mathrm{m}, \mathrm{h}=5 \mu \mathrm{m}, \mathrm{i}=10 \mu \mathrm{m}$. 

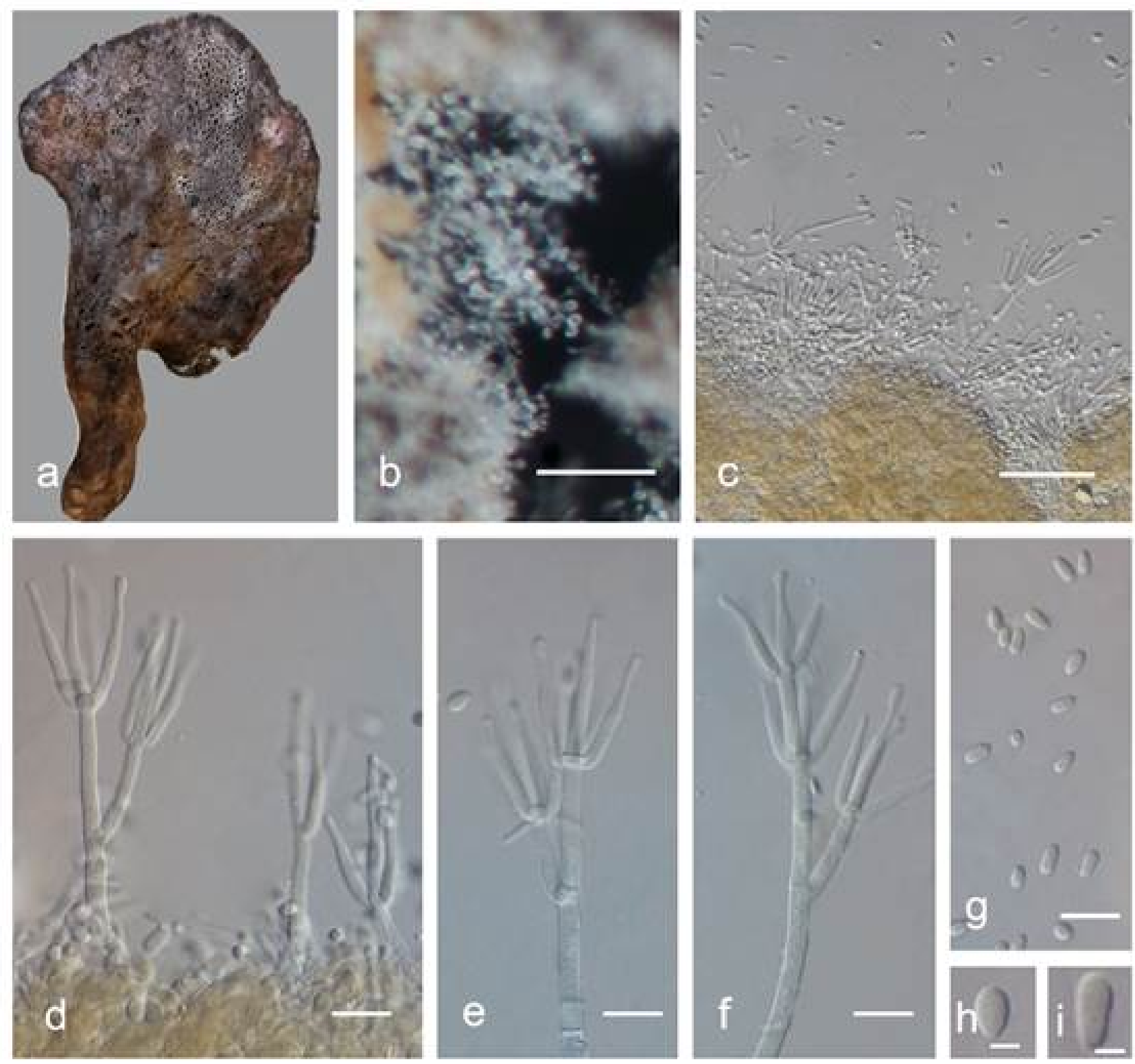

Fig. 13 - Paecilomyces formosus (CGMCC 3.19066). a White colony on the fruiting body of Fistulina sp. c Conidiophores. d-f Phialides. g-i Conidia. Scale bars: $b=2000 \mu \mathrm{m}), \mathrm{c}=25 \mu \mathrm{m}$, $\mathrm{d}-\mathrm{g}=10 \mu \mathrm{m}, \mathrm{h}-\mathrm{i}=2 \mu \mathrm{m}$.

Paecilomyces hepiali Q.T. Chen \& R.Q. Dai ex R.Q. Dai, X.M. Li, A.J. Shao, Shu F. Lin, J.L. Lan, Wei H. Chen \& C.Y. Shen, Mycosystema 27(5): 642 (2008)

Facesoffungi number: FoF 06018

Fungicolous on sclerotium and stroma of Ophiocordyceps sinensis. Asexual morph: Conidiophores hyaline, branched, with 2-3 whorls. Phialides hyaline, monothetic, opposite or alternate, occurring directly on aerial hyphae, sometimes born on simple conidiophores with 1-5 whorls; narrowly lageniform, normally with a thin neck, tapering gradually from the base to the tip, sometimes with a swollen basal portion, tapering abruptly at the tip, basipetally yielding the catenate conidia, 5.0-25 $\times 1.0-3.0 \mu \mathrm{m}(\bar{x}=8 \mu \mathrm{m}, \mathrm{n}=30)$. Conidia hyaline, ovoid or oblong, smooth-walled, 3-4 × 2-3.0 $\mu \mathrm{m}(\bar{x}=3.5 \times 2.5 \mu \mathrm{m}, \mathrm{n}=30)$. Sexual morph: Undetermined.

Material examined - CHINA, Guang Dong Province, Dongguan City, on a fruiting body of cultivated Ophiocordyceps sinensis. 12 December 2015; Sun J. Z. Living culture CGMCC 3.19068). GenBank no. (ITS: MH459159, and TEF: MH464778) 
Notes - Paecilomyces hepiali was previously isolated from stomata of Ophiocordydeps sinensis and body of Hepialus armorianus Oberthiir in Yunnan Province (Dai et al. 1989, 2008). This fungus differs from Paecilomyces xylariiformis (Lloyd) Samson (Basionym: Isaria xylariiformis Lloyd) in the shape and size of conidia and host insect association (Dai et al. 1989). It differs from Isaria farinosa (Basionym: Paecilomyces farinosus (Holmsk.) A.H.S.Br. \& G.Sm) in the shape and arrangement of phialides, the shape of conidia, and also in its host (Hapialus) and habitat (Dai et al. 1989, Wang et al. 2015). Our isolate produces the Paecilomyces-like or Isarialike conidiophores and ovoid conidia (Fig. 14), which resembles $P$. hepialid; and the ITS sequence also indicates it belongs to the $P$. hepiali. Previous phylogenetic analysis supported that $P$. hepiali belongs to Hypocreales but is not the asexual stage of $O$. sinensis (Wei et al. 2005, Wang et al. 2015). In this study, phylogeny based on combined ITS and TEF sequence data shows our isolate clusters with $P$. hepiali including the type strain with strong support (99\% BSML, 1.00 BYPP, Fig. S6), suggesting a new collection of $P$. hepiali. The phylogenetic analysis also indicates that $P$. hepiali is congeneric with Isaria. However, $P$. hepiali is an important medicinal fungus in China, herein we report it as fungicolous fungus and follow its original name.

Polycephalomyces sinensis (Q.T. Chen, S.R. Xiao \& Z.Y. Shi) W.J. Wang, X.L. Wang, Y. Li, S.R. Xiao \& Y.J. Yao, Systematics and Biodiversity 10(2): 228 (2012).

Fig. 15

Facesoffungi number: FoF 06019

Fungicolous, form cottony layer on the stromata of Ophiocordyceps sinensis. Asexual morph: Mycelium 2-3 $\mu \mathrm{m}$ wide, septate, branched, smooth-walled. Conidiophores hyaline, erect, occasionally verticillate $18-70 \times 2-3.5 \mu \mathrm{m}(\bar{x}=55 \times 3 \mu \mathrm{m}, \mathrm{n}=20)$, with $1-2$ verticils. Phialides hyaline, acropleurogenous, monophialidic, opposite or alternate, lanceolate, 18-70 × 2-3.5 $\mu \mathrm{m}(\bar{x}$ $=55 \times 3 \mu \mathrm{m}, \mathrm{n}=20$ ), gradually tapering near the apex, basipetally yielding the catenulate conidia. Conidia unicellular, hyaline, ovoid, or fusiform, base acuminate, aseptate, thin-walled, smoothwalled, 3.5-5 × 1.5-2 $\mu \mathrm{m}(\bar{x}=4.2 \times 1.8 \mu \mathrm{m}, \mathrm{n}=30)$. Sexual morph: Undetermined.

Material examined - CHINA, Tibet, Ling Zhi city, on a fruiting body of cultivated Ophiocordyceps sinensis. 6 June 2014; Sun J. Z. (HMAS 281237), living culture CGMCC 3.19069. GenBank no. (ITS: MH459160, and SSU: MH454346).

Notes - Polycephalomyces sinensis was previously described as a new taxon, namely, Paecilomyces sinensis, different from the asexual stage of Cordyceps militaris (L.) Link, with respect to conidial features, phialide size, host and habitual characters (Chen et al. 1984, Liang et al. 2005). It was once considered as the possible asexual stage of Ophiocordyceps sinensis (Chen et al. 1984). Recently, the phylogenetic analysis demonstrated it is a clavicipitaceous fungus other than a species within Ophiocordycipitaceae (Wang et al. 2012). Since previous studies and this research found that $P$. sinensis always occurs associated with $O$. sinensis, it is considered as fungicolous taxon here. Our fungus produces the Paecilomyces-like conidiophores and ovoid conidia (Fig. 15), which is similar to Polycephalomyces; and the ITS sequence indicates it belongs to the $P$. sinensis. The phylogenetic analysis presents our isolate clusters with strains of $P$. sinensis with strong support (97\% BSML, 1.00 BYPP, Fig. S7). Therefore, our taxon is named P. sinensis. In addition, our result confirms that $P$. sinensis is a fungicolous fungus rather than the asexual stage of $O$. sinensis.

Sporothrix ganoderma. Jing Z. Sun, Xing Z. Liu \& K.D. Hyde sp. nov.

Fig. 16

MycoBank number: MB827518; Facesoffungi number: FOF 06028

Etymology - The epithet ganoderma refers to the generic name of host-fungus

Fungicolous, growing on the fruiting body of Ganoderma lucidum. Asexual morph: Hyphomycetous. Conidiomata synnematous, scattered, dark brown to blackish. Synnemata, 700$1150 \times 15-45 \mu \mathrm{m}(\bar{x}=1000 \times 25 \mu \mathrm{m}, \mathrm{n}=10)$, determinate, erect, straight, composed of tightly adpressed filaments, forming a firm subcylindrical, dark brown stipe, broadly rounded at base, with a tight capitulum, with apically divergent conidiophores. Conidiophores $2-3 \mu \mathrm{m}(\bar{x}=2.5 \mu \mathrm{m}, \mathrm{n}=$ 10) wide, individually filiform, unbranched, pluriseptate, dark brown below and pale brown to 
hyaline above, smooth. Conidiogenous cells mono- to polyblastic, sympodial, integrated, terminal, hyaline, and smooth-walled, 6-8 $\times 2-3 \mu \mathrm{m}(\bar{x}=7 \times 2.5 \mu \mathrm{m}, \mathrm{n}=30)$. Conidia acrogenous, hyaline, simple, aseptate, smooth, clavate to fusiform, 6-7.5 $\times 1.5-2.5 \mu \mathrm{m}(\bar{x}=7.2 \times 2.1 \mu \mathrm{m}, \mathrm{n}=30)$. Sexual morph: Ascomata 100-120 $\mu \mathrm{m}$ diam., formed on host fruiting body, with bases black or dark-brown, globose. Ascomatal necks smooth, dark, straight or slightly curved, tapering at apex. Asci evanescent. Ascospores hyline, simple, aseptate, smooth, cylindrical, clavate, mostly curved, $3.5-7 \times 1.2-1.5 \mu \mathrm{m}(\bar{x}=4.2 \times 1.3 \mu \mathrm{m}, \mathrm{n}=30)$.
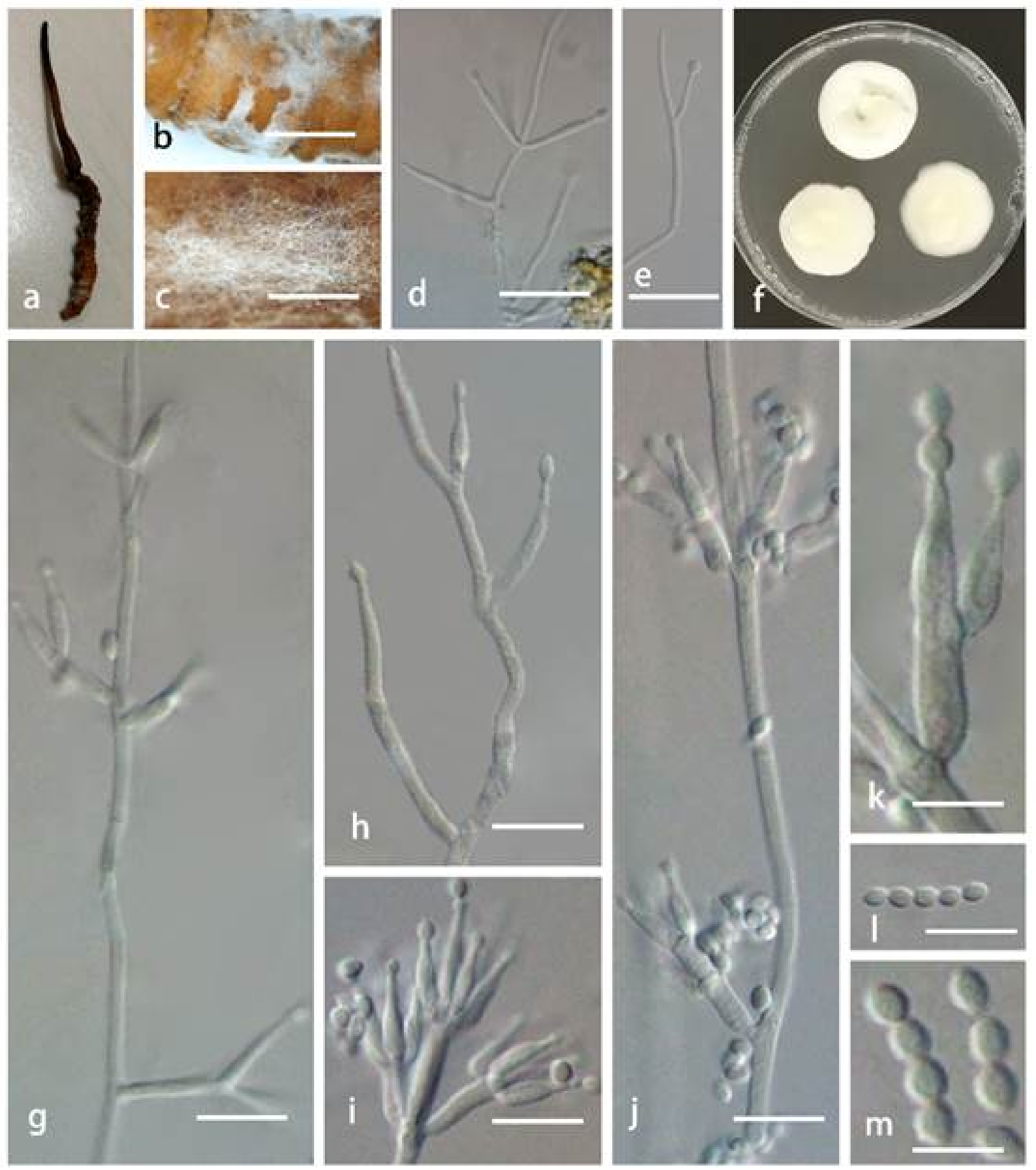

Fig. 14 - Paecilomyces hepiali (CGMCC 3.19068). a Cultivated Ophiocordyceps sinensis. b Mycelium on sclerotium of Ophiocordyceps sinensis. c Mycelia on stroma of Ophiocordyceps sinensis $\mathrm{f}$ Colony of $\mathrm{P}$. hepiali on PDA at $18{ }^{\circ} \mathrm{C}$ after 14 days. d, e, g, h. Conidiophores. i-k Phialides with conidia. l, m Conidia. Scale bars: $\mathrm{b}=200 \mu \mathrm{m}), \mathrm{c}=100 \mu \mathrm{m}, \mathrm{d}, \mathrm{e}=20 \mu \mathrm{m}$, $\mathrm{g}-\mathrm{m}=10 \mu \mathrm{m}$. 

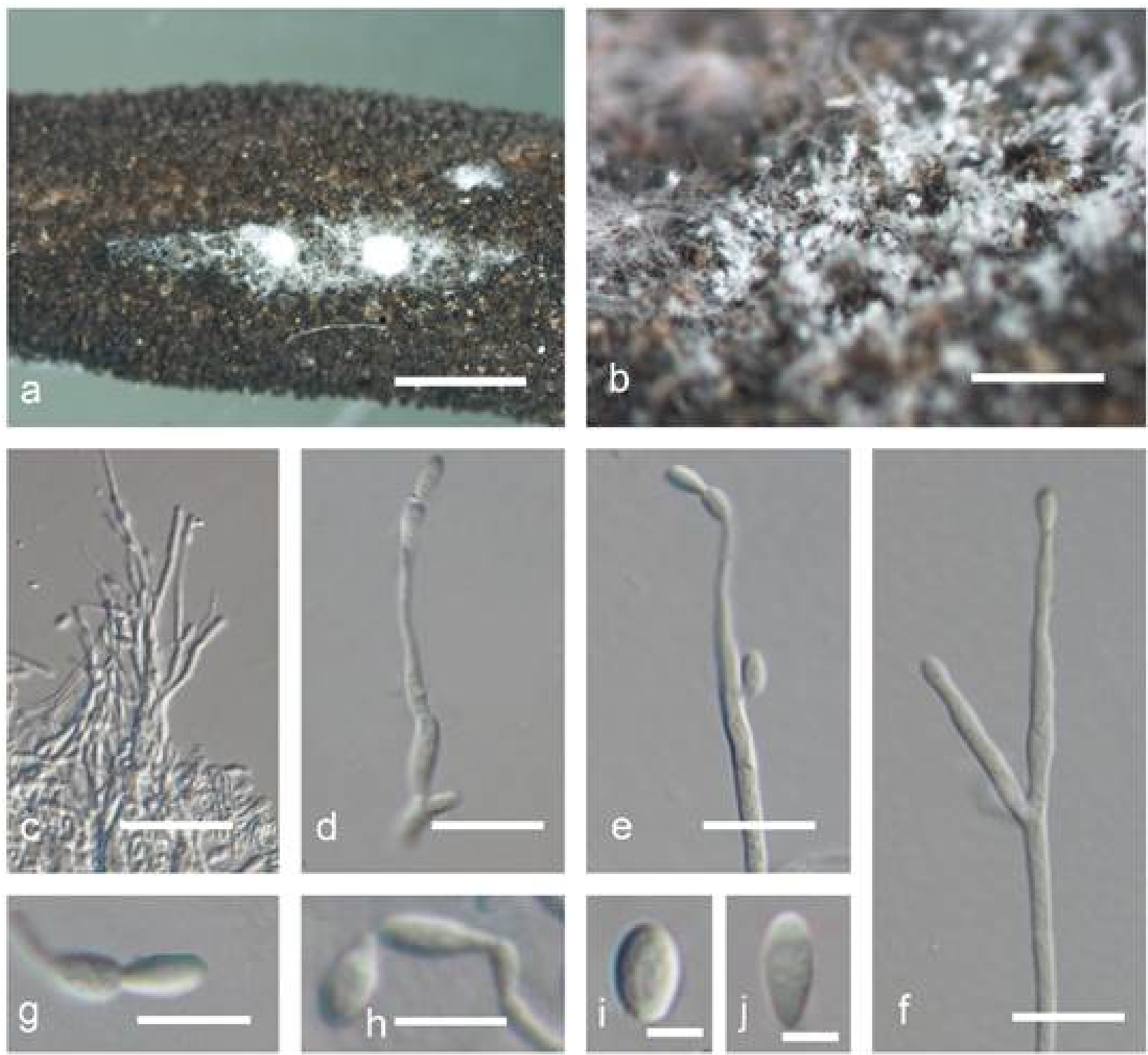

Fig. 15 - Polycephalomyces sinensis (CGMCC 3.19069). a, b Colony on sclerotium of Ophiocordyceps sinnesis. c Conidiophores. $\mathrm{d}-\mathrm{f}$ Conidiogenous cell. g, h Conidia. Scale bars: $\mathrm{a}=2$ $\mathrm{mm}, \mathrm{b}=200 \mu \mathrm{m}, \mathrm{c}=25 \mu \mathrm{m}, \mathrm{d}-\mathrm{f}=10 \mu \mathrm{m}, \mathrm{g}, \mathrm{h}=5 \mu \mathrm{m}, \mathrm{i}, \mathrm{j}=2 \mu \mathrm{m}$

Material examined - CHINA, Sichuan Province, on the fruiting body of Ganoderma lucidum, 4 August 2015, Dong C. H. (HMAS 255369, holotype; isotope HKAS 104961), GenBank no. (ITS: MH459161, and LSU: MH459166).

Notes - Phylogenetic analysis based on LSU indicates that Sporothrix distincts from Ophiostoma s. str. given that Sporothrix formed a well-supported monophyletic lineage (De Beer et al. 2016). Currently, Sporothrix contains 51 Sporothrix which are human pathogens, plant pathogens, insect pathogens, and fungicolous species as well (Constantinescu \& Ryman 1989, De Beer et al. 2016, Ngubane et al. 2018). In this study, our fungus produces Ophiostoma-like ascomata and conidiophores (Fig. 16). Phylogenetic analysis based on combined ITS and LSU sequence dataset suggests our collections belongs to Sporothrix. In addition, our collections groups with $S$. nebularis complex but differs from S. nebularis complex (Fig. 2). Despite they show close phylogenetic affinities to S. nigrograna (Masuya et al. 2003) and S. nebularis (Romón et al. 2014, De Beer et al. 2016), but differs from the later by producing larger fusiform conidia. Combined the phylogenetic and morphological evidence, Sporothrix ganoderma is introduced herein. 

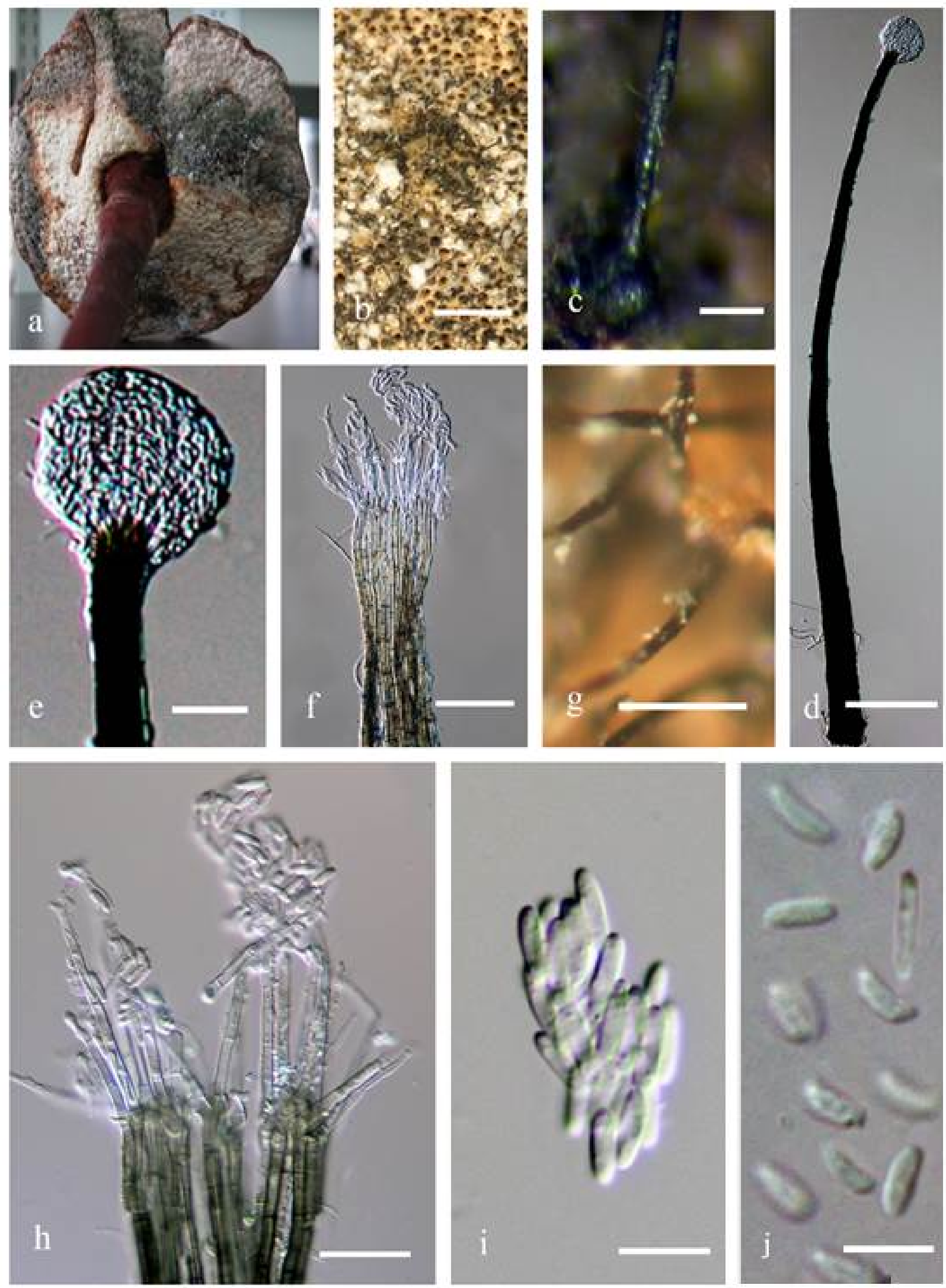

Fig. 16 - Sporothrix ganoderma (HMAS 255369). a Colony on fruiting of Ganoderma lucidum and associated with Trichoderma. b Ascomata on Ganoderma lucidum. c Base of ascomata d Synnemata. e, f Conidiogenous cells. g partial Ascomatal necks. h Conidiogenous and conidia. i Conidia. j Ascospore. Scale bars: $\mathrm{b}=2 \mathrm{~mm}, \mathrm{c}, \mathrm{d}=100 \mu \mathrm{m}, \mathrm{e}, \mathrm{f}=50 \mu \mathrm{m}, \mathrm{g}=200 \mu \mathrm{m}, \mathrm{h}=20 \mu \mathrm{m}$, $\mathrm{i}=10 \mu \mathrm{m}, \mathrm{j}=5 \mu \mathrm{m}$. 
Trichoderma atrobrunneum F.B. Rocha, P. Chaverri \& W. Jaklitsch, Mycologia 107(3): 571 (2014)

Facesoffungi number: FoF 06020

Fig. 17

Fungicolous on a fruiting body of Ganoderma lucidum in terrestrial habitats. Asexual morph: Conidiophores hyaline, pyramidal with opposing branches, each branch terminating in a whorl, whorls typically cruciate but often nearly verticillate, with 2-5 phialides. Phialides hyaline, solitary from the main axis, ampulliform to lageniform, typically constricted below the tip to form a narrow neck, $5.0-9.5 \times 3.0-4.0 \mu \mathrm{m}(\bar{x}=6.5 \times 3.2 \mu \mathrm{m}, \quad \mathrm{n}=20)$. Conidia hyaline when young, becoming green to dark green with age, globose, subglobose, aseptate, smooth-walled, $2.0-3 \times 1.8-2.5 \mu \mathrm{m}(\bar{x}$ $=2.5 \times 2.2 \mu \mathrm{m}, \mathrm{n}=30$ ). Sexual morph: Undetermined.
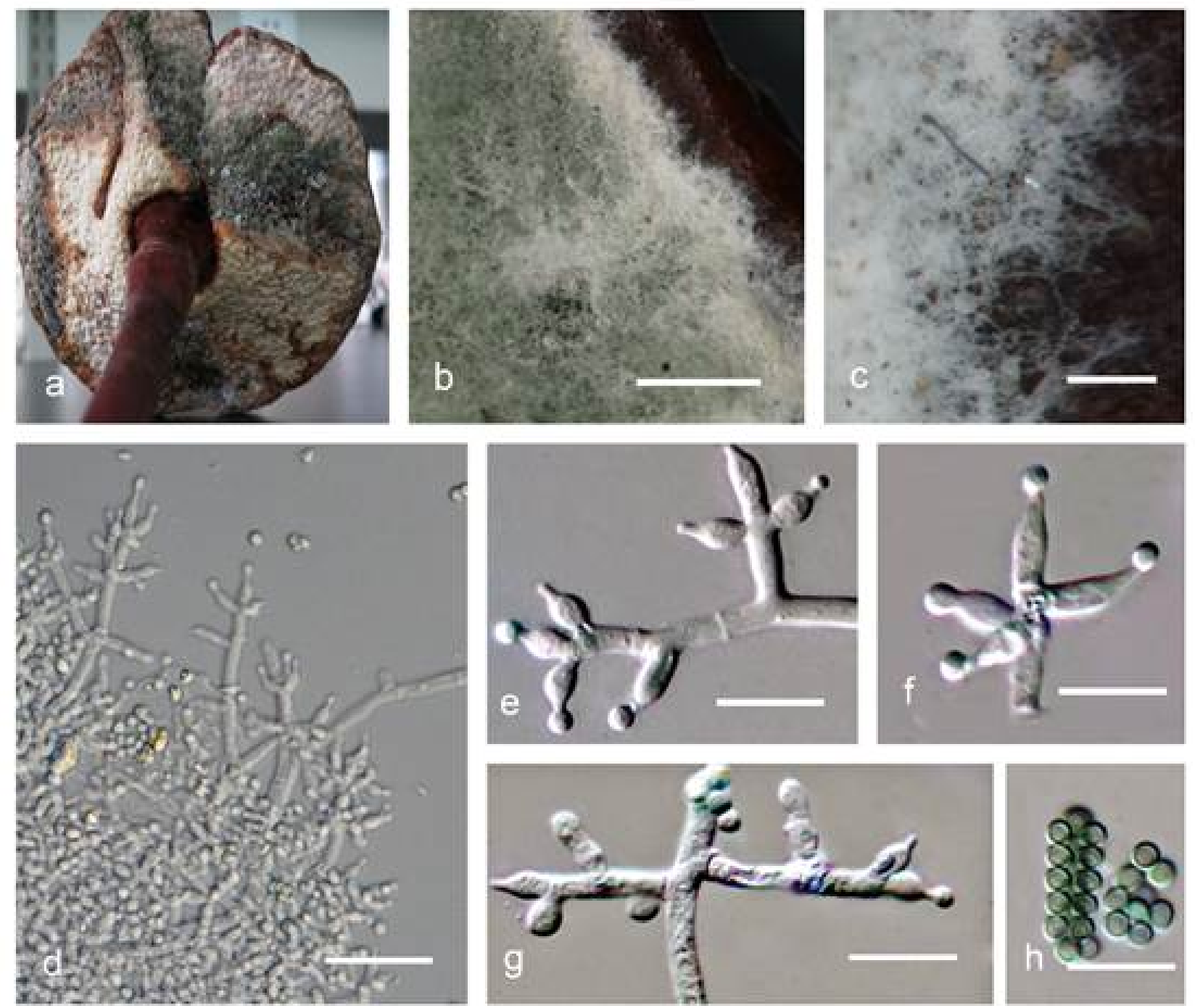

Fig. 17 - Trichoderma atrobrunneum (HMAS 255368). a-c Colony on fruiting of Ganoderma lucidum. d, e Conidiophores. f, g Phialides. h Conidia. Scale bars: $\mathrm{a}=2 \mathrm{~mm}, \mathrm{c}=500 \mu \mathrm{m}, \mathrm{d}=25$ $\mu \mathrm{m}, \mathrm{e}-\mathrm{d}=10 \mu \mathrm{m}$.

Material examined - CHINA, Sichuan Province, on a fruiting body of cultivated Ganoderma lucidum. 17 August 2015; Dong C. H. (HMAS 255368), living culture CGMCC 3.19070. GenBank no. (ITS: MH459162, and TEF: MH464779).

Notes - Our fungus produces Trichoderma-like conidiophores and hyaline or green globose conidia (Fig. 17). The ITS sequence indicates it belongs to Trichoderma harzianum species complex. Members in Trichoderma harzianum species complex are fungicoloes (Kubicek et al. 2011, Chaverri \& Samuels 2013) and have been explored as biocontrol agents (Castrillo et al. 
2016). Phylogenetic analysis based on ITS and TEF sequences have revealed 14 species from $T$. harzianum complex including T. atrobrunneum (Chaverri et al. 2015). In this study, our taxon groups with the type strain of T. atrobrunneum with strong support (Fig. S8, 91\% BSML/1.00 BYPP). Therefore, it is regarded as Trichoderma atrobrunneum. It is a new fungicolous taxon in China. Because it infects the cultivated Ganoderma lucidum, it could be a potential fungal pathogen of G. lucidum.

\section{Conclusion}

Edible and medicinal mushrooms become a very important crop and are grown commercially in many countries (Fletcher \& Gaze 2007, Dong et al. 2015). China and Thailand are two major mushroom producers and consumer (Zhang et al. 2015). However, the production including the yield and quantity are challenged by the fungal disease (Zhang et al. 2015, Dong et al. 2015, Sun et al. 2019). In this study, fifteen fungicolous taxa from eleven edible and medicinal mushroom were identified. Thirteen of them are Sordariomycetes including twelve Hypocrealean fungi and one Ophiostomatalean fungus, as well as two Eurotiomycetes. Among these taxa, several species of Hypomyces, Lecanicillium, and Trichoderma have been reported as the causing agent cobweb disease, dry bubble disease and green mold disease of mushrooms (Zare \& Gams 2008, Põldmaa 2011, Tamm \& Põldmaa 2013, Jaklitsch \& Voglmayr 2015, Carrasco et al. 2016), individually. In addition, the fungicolous Aspergillus and Paecilomyces colonized on the fruiting body of mushrooms are considered to be the saprobes that associated with their host. Compared the previous studies, these results reveal genetic variation and geographic differentiation of the fungi associated with mushrooms in China and Thailand, which enhance our current knowledge on taxonomic diversity of fungicolous fungi in these regions. Since these fungicolous taxa could be found on a wild mushroom, as well as a cultivated mushroom (Tamm \& Põldmaa 2013, Jaklitsch \& Voglmayr 2015, Sun et al. 2016, 2017, 2019). They are not merely the potential threaten in mushroom harvest and cultivation, but a bottleneck of demonstration of wild mushroom.

\section{Acknowledgments}

This research was jointly supported by the Natural Science Foundation of China (no. 31600024) and Key Research \& development and Technical transformation Plan of Qing Hai Province (no. 2017-SF-118). The authors would like to thank Prof. Darbhe J. Bhat for correction of the fungal description.

\section{References}

Abreu LM, Moreira GM, Ferreira D, Rodrigues-Filho E et al. 2014 - Diversity of Clonostachys species assessed by molecular phylogenetics and MALDI-TOF mass spectrometry. Fungal Biology 118(12), 1004-11012.

Bhattacharya D, Lutzoni F, Reeb V, Simon D et al. 2000 - Widespread occurrence of spliceosomal introns in the rDNA genes of ascomycetes. Molecular Biology and Evolution 17(12), 19711984.

Bissett J, Gams W, Jaklitsch W, Samuels GJ. 2015 - Accepted Trichoderma names in the year 2015. IMA Fungus 6(2): 263-295.

Burns C, Geraghty R, Neville C, Murphy A et al. 2005 - Identification, cloning, and functional expression of three glutathione transferase genes from Aspergillus fumigatus. Fungal Genetics and Biology 42(4), 319-27.

Carrasco J, Navarro MJ, Gea FJ. 2017 - Cobweb, a serious pathology in mushroom crops: A review. Spanish Journal of Agricultural Research 15(2), 1-11.

Carrasco J, Navarro MJ, Santos M, Diánez F et al. 2016 - Incidence, identification and pathogenicity of Cladobotryum mycophilum, causal agent of cobweb disease on Agaricus bisporus mushroom crops in Spain. Annals of Applied Biology 168 (2), 214-224. 
Castresana J. 2000 - Selection of conserved blocks from multiple alignments for their use in phylogenetic analysis. Molecular Biology and Evolution 17(4): 540-552.

Castrillo ML, Bich GA, Zapata PD, Villalba LL. 2016 - Biocontrol of Leucoagaricus gongylophorus of leaf-cutting ants with the mycoparasitic agent Trichoderma koningiopsis. Mycosphere 7(6), 810-819.

Chaverri P, Branco-Rocha F, Jaklitsch W, Gazis R et al. 2015 - Systematics of the Trichoderma harzianum species complex and the re-identification of commercial biocontrol strains. Mycologia 107(3), 558-590.

Chaverri P, Samuels GJ 2013 - Evolution of habitat preference and nutrition mode in a cosmopolitan fungal genus with evidence of interkingdom host jumps and major shifts in ecology. Evolution 67(10), 2823-2837.

Chen QT, Xiao SR, Shi ZY. 1984 - Paecilomyces sinensis sp. nov. and its connection with Cordyceps sinensis. Acta Mycologica Sinica 3, 24-28. (in Chinese)

Chen AJ, Hubka V, Frisvad JC, Visagie CM et al. 2017 - Polyphasic taxonomy of Aspergillus section Aspergillus (formerly Eurotium), and its occurrence in indoor environments and food. Studies in mycology, 88, 37-135.

Chomnunti P, Hongsanan S, Aguirre-Hudson B, Tian Q et al. 2014 - The sooty moulds. Fungal Diversity 66 (1):1-36.

Constantinescu O, Ryman S. 1989 - A new Ophiostoma on polypores. Mycotaxon 34: 637-642.

Dai RQ, Lan JL, Chen WH, Li XM et al. 1989 - Research on Paecilomyces hepiali Chen et Dai, sp. nov. A. Acta Agriculturea Universitatis Pekinensis 15(2), 221-224. (in Chinese)

Dai RQ, Li XM, Lan JL, Shao AJ, Lin SF et al. 2008 - Nomenclatural validation of Paecilomyces hepiali. Mycosystema 27, 641-644. (in Chinese)

De Beer ZW, Duong TA, Wingfield MJ. 2016 - The divorce of Sporothrix and Ophiostoma: solution to a problematic relationship. Studies in Mycology 83, 165-191.

De Beer ZW, Seifert K, Wingfield M. 2013 - A nomenclator for ophiostomatoid genera and species in the Ophiostomatales and Microascales. Ophiostomatoid fungi: Expanding frontiers Utrecht, CBS-KNAW Fungal Biodiversity Centre CBS Biodiversity Series 12, 261-268.

Dong CH, Guo SP, Wang W, Liu XZ. 2015 - Cordyceps industry in China. Mycology 6(2), 121129.

Du XH, Zhao Q, Yang ZL. 2015 - A review on research advances, issues, and perspectives of morels. Mycology 6(2), 78-85.

Fletcher JT, Gaze RH. 2007 - Fungal disease In: Fletcher JT, Gaze RH (eds) Mushroom pest and disease control: a colour handbook. CRC Press, London, pp 63-92.

Gams W, Diederich P, Põldamaa K. 2004 - Fungicolous fungi. In: Mueller GM, Bills GF, Foster MS (eds) Biodiversity of fungi inventory and monitoring methods. Elsevier Academic Press, USA, pp 343-392.

Hatvani L, Antal Z, Manczinger L, Szekeres A et al. 2007 - Green mold diseases of Agaricus and Pleurotus spp. are caused by related but phylogenetically different Trichoderma species. Phytopathology 97(4), 532-537.

Ilic J, Cosic J, Vrandecic K, Dugalic K et al. 2017 - Influence of endophytic fungi isolated from symptomless weeds on cherry plants. Mycosphere 8(1), 18-30.

Jaklitsch W, Voglmayr H. 2015 - Biodiversity of Trichoderma (Hypocreaceae) in Southern Europe and Macaronesia. Studies in Mycology 80, 1-87.

Jayasiri SC, Hyde KD, Ariyawansa HA, Bhat J et al. 2015 - The Faces of Fungi database: fungal names linked with morphology, phylogeny and human impacts. Fungal Diversity 74(1), 3-18.

Jeewon R, Hyde KD. 2016 - Establishing species boundaries and new taxa among fungi: recommendations to resolve taxonomic ambiguities. Mycosphere 7(11), 1669-1677.

Katoh K, Standley DM. 2013 - MAFFT multiple sequence alignment software version 7: improvements in performance and usability. Molecular biology and evolution 30(4), 772780 . 
Kim CS, Shirouzu T, Nakagiri A, Sotome K et al. 2013 - Trichoderma eijii and T. pseudolacteum, two new species from Japan. Mycological Progress 12(4), 739-753.

Krauss U, Ten Hoopen M, Rees R, Stirrup T et al. 2013 - Mycoparasitism by Clonostachys byssicola and Clonostachys rosea on Trichoderma spp. from cocoa (Theobroma cacao) and implication for the design of mixed biocontrol agents. Biological Control 67(3), 317-327.

Kubicek CP, Herrera-Estrella A, Seidl-Seiboth V, Martinez DA et al. 2011 - Comparative genome sequence analysis underscores mycoparasitism as the ancestral life style of Trichoderma. Genome biology 12(4), R40.

Liang ZQ, Han YF, Chu HL, Liu AY. 2005 - Studies on the genus Paecilomyces in China I. Fungal Diversity 20, 83-101.

Liu YJ, Whelen S, Hall BD. 1999 - Phylogenetic relationships among ascomycetes: evidence from an RNA polymerase II subunit. Molecular Biology and Evolution 16(12), 1799-1808.

Luangsa-ard JJ, Hywel-Jones NL, Samson RA. 2004 - The polyphyletic nature of Paecilomyces sensu lato based on 18S-generated rDNA phylogeny. Mycologia 96(4): 773-780.

Masuya H, Kaneko S, Yamaoka Y. 2003 - Three new Ophiostoma species isolated from Japanese red pine. Mycoscience 44(4), 301-310.

Ngubane NP, Dreyer LL, Oberlander KC, Roets F. 2018 - Two new Sporothrix species from Protea flower heads in South African Grassland and Savanna. Antonie van Leeuwenhoek, 111(6), 965--979.

O’Donnell K. 2000 - Molecular phylogeny of the Nectria haematococca-Fusarium solani species complex. Mycologia, 919-938.

Petrović J, Glamočlija J, Stojković DS, Ćirić A et al. 2013 - Laetiporus sulphureus, edible mushroom from Serbia: Investigation on volatile compounds, in vitro antimicrobial activity and in situ control of Aspergillus flavus in tomato paste. Food and chemical toxicology 59, 97-302.

Põldmaa K. 1996 - A new species of Hypomyces and three of Cladobotryum from Estonia. Mycotaxon 59, 389-405

Põldmaa K. 1999 - The genus Hypomyces (Hypocreales, Ascomycota) and allied fungicolous fungi in Estonia. I. Species growing on aphyllophoralean basidiomycetes. Folia Cryptog Estonia 34, 15-31

Põldmaa K, \& Samuels GJ. 2004 - Fungicolous Hypocreaceae (Ascomycetes: Hypocreales) from Khao Yai National Park, Thailand. Sydowia, 56(1), 79-130

Põldmaa K. 2000 - Generic delimitation of the fungicolous Hypocreaceae. Studies in Mycology 45, 83-94.

Põldmaa K. 2011 - Tropical species of Cladobotryum and Hypomyces producing red pigments. Studies in Mycology 68, 1-34

Posada D. 2008 - jModelTest: phylogenetic model averaging. Molecular biology and evolution 25(7), 1253-1256.

Poomsing P, Pattanapanyasat K, Wongsinkongman P, Soonthornchareonnon N. 2013 - Research and development of Ganoderma lucidum cultivated in Thailand. Mahidol University Journal of Pharmaceutical Sciences 40(3), 1-7.

Rambaut A. 2014 - FigTree v1. 4.2. http://ree.bio.ed.ac.uk/software/fgtree/

Rehner SA, Buckley E. 2005 - A Beauveria phylogeny inferred from nuclear ITS and EF1- $\alpha$ sequences: evidence for cryptic diversification and links to Cordyceps teleomorphs. Mycologia 97(1), 84-98.

Rogerson CT, Samuels GJ. 1989 - Boleticolous species of Hypomyces. Mycologia 83(3), 413-432. Rogerson CT, Samuels GJ. 1993 - Polyporicolous species of Hypomyces. Mycologia 85(2), 231272.

Rogerson CT, Samuels GJ. 1994 - Agaricicolous species of Hypomyces. Mycologia 86(6), 839866. 
Romón P, de Beer ZW, Zhou X, Duong TA et al. 2014 - Multigene phylogenies of Ophiostomataceae associated with Monterey pine bark beetles in Spain reveal three new fungal species. Mycologia 106(1), 119-132.

Ronquist F, Teslenko M, Van Der Mark P, Ayres DL et al. 2012 - MrBayes 3.2: efficient Bayesian phylogenetic inference and model choice across a large model space. Systematic biology 61(3), 539-542.

Rossman AY, Seifert KA, Samuels GJ, Minnis AM et al. 2013 - Genera in Bionectriaceae, Hypocreaceae, and Nectriaceae (Hypocreales) proposed for acceptance or rejection. IMA Fungus 4(1), 41-51.

Sahr T, Ammer H, Besl H, Fischer M. 1999 - Infrageneric classification of the boleticolous genus Sepedonium: species delimitation and phylogenetic relationships. Mycologia 91(6), 935-943.

Samson RA, Houbraken J, Varga J, Frisvad JC. 2009 - Polyphasic taxonomy of the heat resistant ascomycete genus Byssochlamys and its Paecilomyces anamorphs. Persoonia 22, 14-27.

Schroers HJ. 2001 - A monograph of Bionectria (Ascomycota, Hypocreales, Bionectriaceae) and its Clonostachys anamorphs. Studies in Mycology 46, 1-214.

Schroers HJ, Samuels GJ, Zhang N, Short DP et al. 2016 - Epitypification of Fusisporium (Fusarium) solani and its assignment to a common phylogenetic species in the Fusarium solani species complex. Mycologia 108(4), 806-819.

Silvestro D, Michalak I. 2012 - raxmlGUI: a graphical front-end for RAxML. Organisms Diversity \& Evolution 12(4), 335-337.

Sun JZ, Dong CH, Liu XZ, Liu JK et al. 2016 - Calcarisporium cordycipiticola sp. nov., an important fungal pathogen of Cordyceps militaris. Phytotaxa 268 (2), 135-144.

Sun JZ, Liu XZ, Hyde KD, Zhao Q et al. 2017 - Calcarisporium xylariicola sp. nov. and introduction of Calcarisporiaceae fam. nov. in Hypocreales. Mycological Progress 4(16), 433-445.

Sun JZ, Liu XZ, McKenzie EHC, Jeewon R et al. 2019 - Fungicolous fungi: terminology, diversity, distribution, evolution, and species checklist. Fungal Diversity 94(2). Doi:` 10.1007/s13225-019-00422-9

Sung GH, Hywel-Jones NL, Sung JM, Luangsa-ard JJ et al. 2007 - Phylogenetic classification of Cordyceps and the clavicipitaceous fungi. Studies in Mycology 57: 5-59.

Tamm H, Põldmaa K. 2013- Diversity, host associations, and phylogeography of temperate aurofusarin-producing Hypomyces/Cladobotryum including causal agents of cobweb disease of cultivated mushrooms. Fungal Biology 117(5), 348-367.

Vaidya G, Lohman DJ, Meier R. 2011 - SequenceMatrix: concatenation software for the fast assembly of multi-gene datasets with character set and codon information. Cladistics 27(2), 171-180.

Visagie CM, Yilmaz N, Renaud JB, Sumarah MW et al. 2017 - A survey of xerophilic Aspergillus from indoor environment, including descriptions of two new section Aspergillus species producing eurotium-like sexual states. Mycokeys 19, 1-30.

Wang WJ, Li Y, Wang XL, Kirk PM et al. 2015 - Neotypification of Paecilomyces hepiali (Hypocreales). Taxon 64(1): 147-150.

Wang WJ, Wang XL, Li Y, Xiao SR et al. 2012 - Molecular and morphological studies of Paecilomyces sinensis reveal a new clade in clavicipitaceous fungi and its new systematic position. Systematics and Biodiversity 10(2), 221-32.

Wei X, Yin X, Guo Y, Shen N et al. 2005 - Analyses of molecular systematics on Cordyceps sinensis and its related taxa. Mycosystema 25(2), 192-202.

White TJ, Bruns T, Lee S, Taylor J. 1990 - Amplification and direct sequencing of fungal ribosomal RNA genes for phylogenetics. PCR protocols: a guide to methods and applications 18(1), 315-322.

Wijayawardene NN, Hyde KD, Rajeshkumar KC, Hawksworth DL et al. 2017a - Notes for genera: Ascomycota. Fungal Diversity 86, 1-594 
Wijayawardene NN, Hyde KD, Tibpromma S, Wanasinghe DN et al. 2017b - Towards incorporating asexual fungi in a natural classification: checklist and notes 2012-2016. Mycosphere 8: 1457-1555. https://doi.org/10.5943/mycosphere/8/9/10

Wu G, Zhao K, Li YC, Zeng NK et al. 2016 - Four new genera of the fungal family Boletaceae. Fungal Diversity 81(1): 1-24.

Zare R, Gams W. 2008 - A revision of the Verticillium fungicola species complex and its affinity with the genus Lecanicillium. Mycological Research 112, 811-824.

Zhang JX, Chen Q, Huang CY, Gao W et al. 2015 - History, current situation and trend of edible mushroom industry development. Mycosystema 34(4), 524-540.

Zhang WW, Zhang XL, Li K, Wang CH et al. 2018 - Introgression and gene family contraction drive the evolution of lifestyle and host shifts of hypocrealean fungi. Mycology 9(3), 1-13.

Zhu ZX, Zhuang WY. 2013 - Resources of nonlichenized fungicolous Ascomycota from China. Mycosystema 32 (S1), 79-88. 


\section{Supplementary Figures S1-S8}

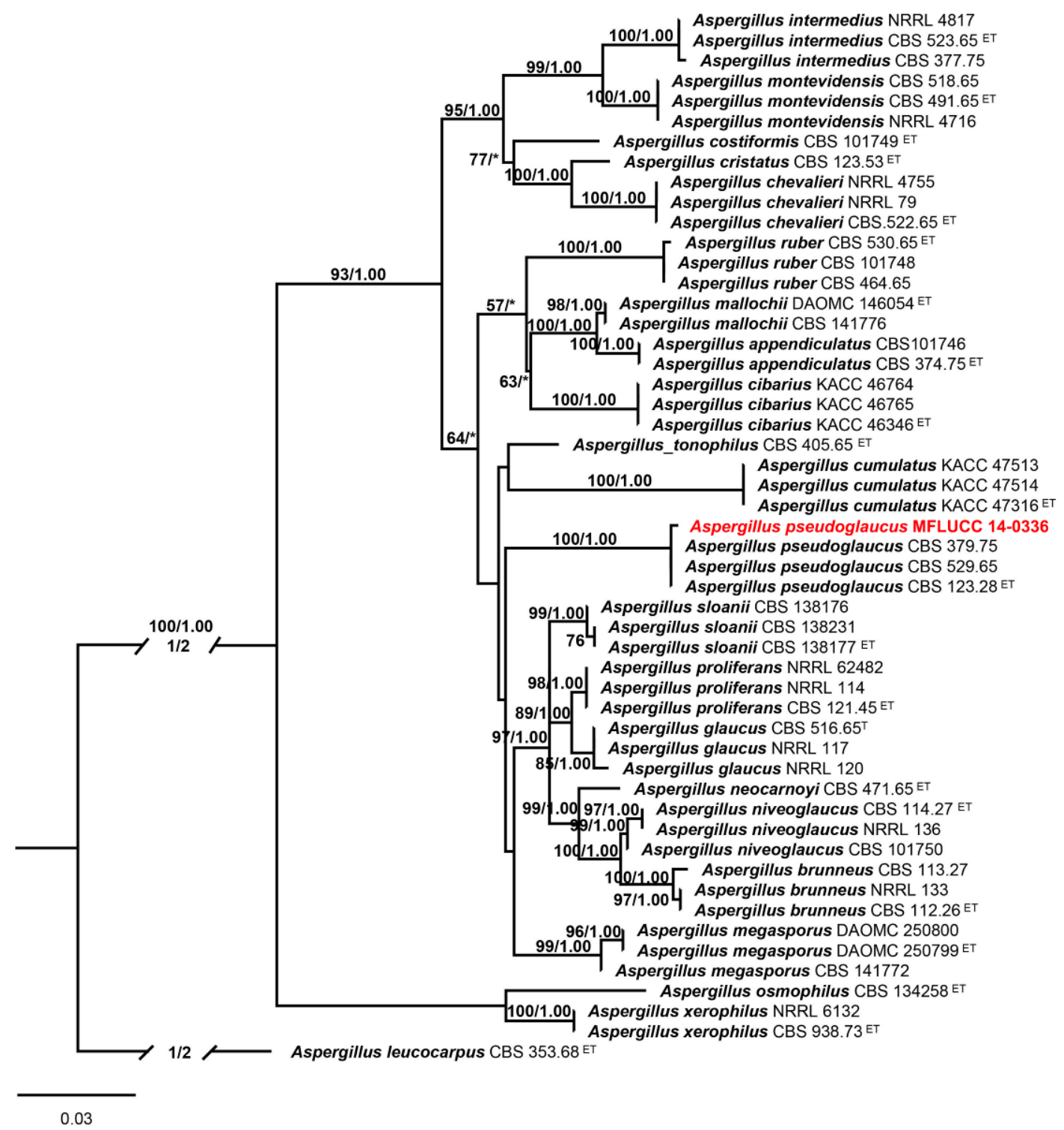

Fig. S1 - Phylogram generated by maximum likelihood analysis based on combined ITS and sequence data. The tree is rooted with Aspergillus leucocarpus. Bootstrap values higher than 50\% from RAxML (BSML) (left) are given above the nodes. Bayesian posterior probabilities greater than 0.95 are indicated (BYPP) (right). Asterisks indicate bootstrap values of less than $50 \%$ or Bayesian posterior probabilities lower than $0.95 .^{\mathrm{T}}$ indicates type. Our collection is red. 


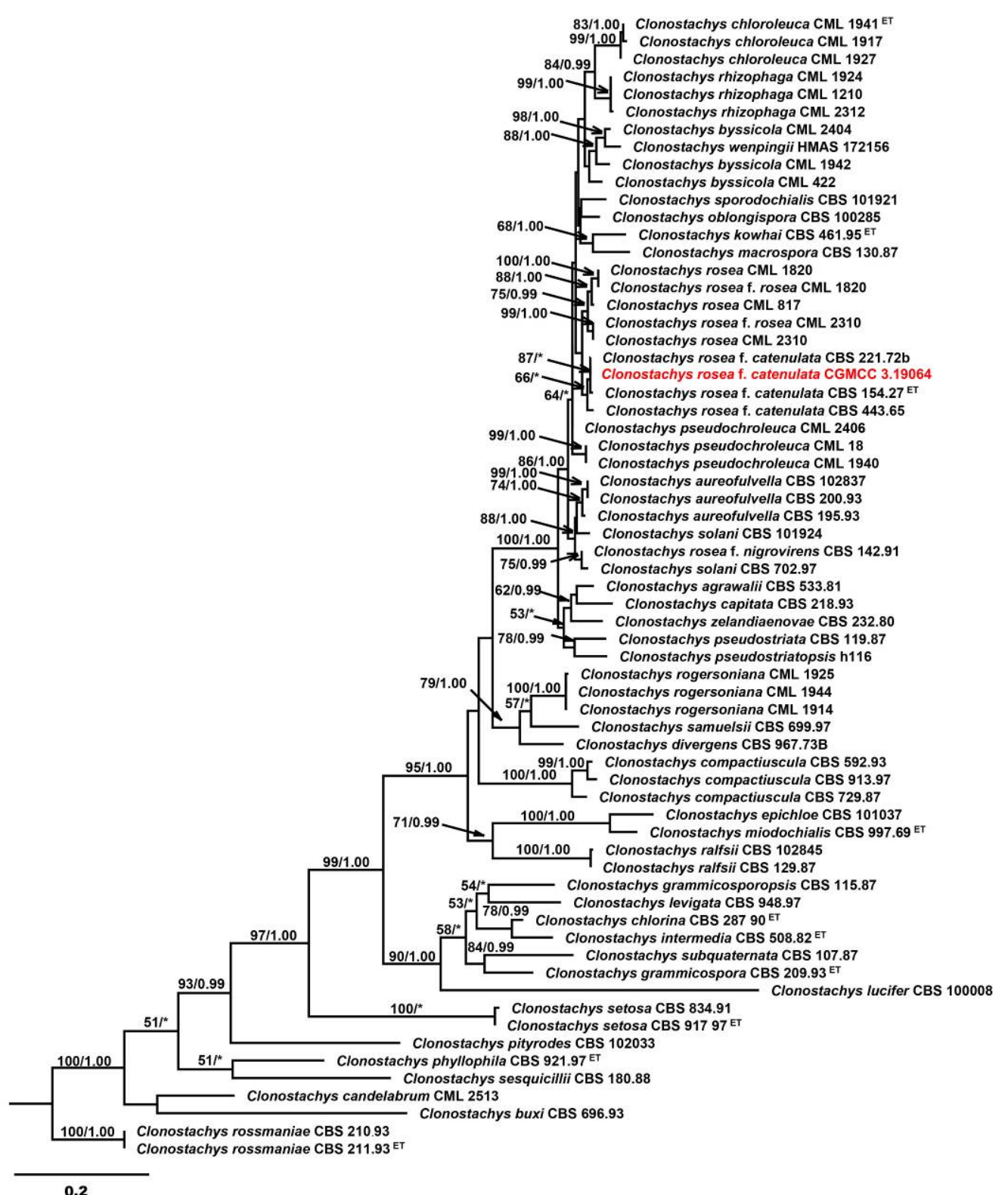

0.2

Fig. S2 - Phylogram generated by maximum likelihood analysis based on a combination of ITS and TUB sequence data. The tree is rooted with Clonostachys rossmaniae. Bootstrap values higher than $50 \%$ from RAxML (BSML) are given above or under the nodes. ${ }^{\mathrm{T}}$ indicates type. Our collection is red. 


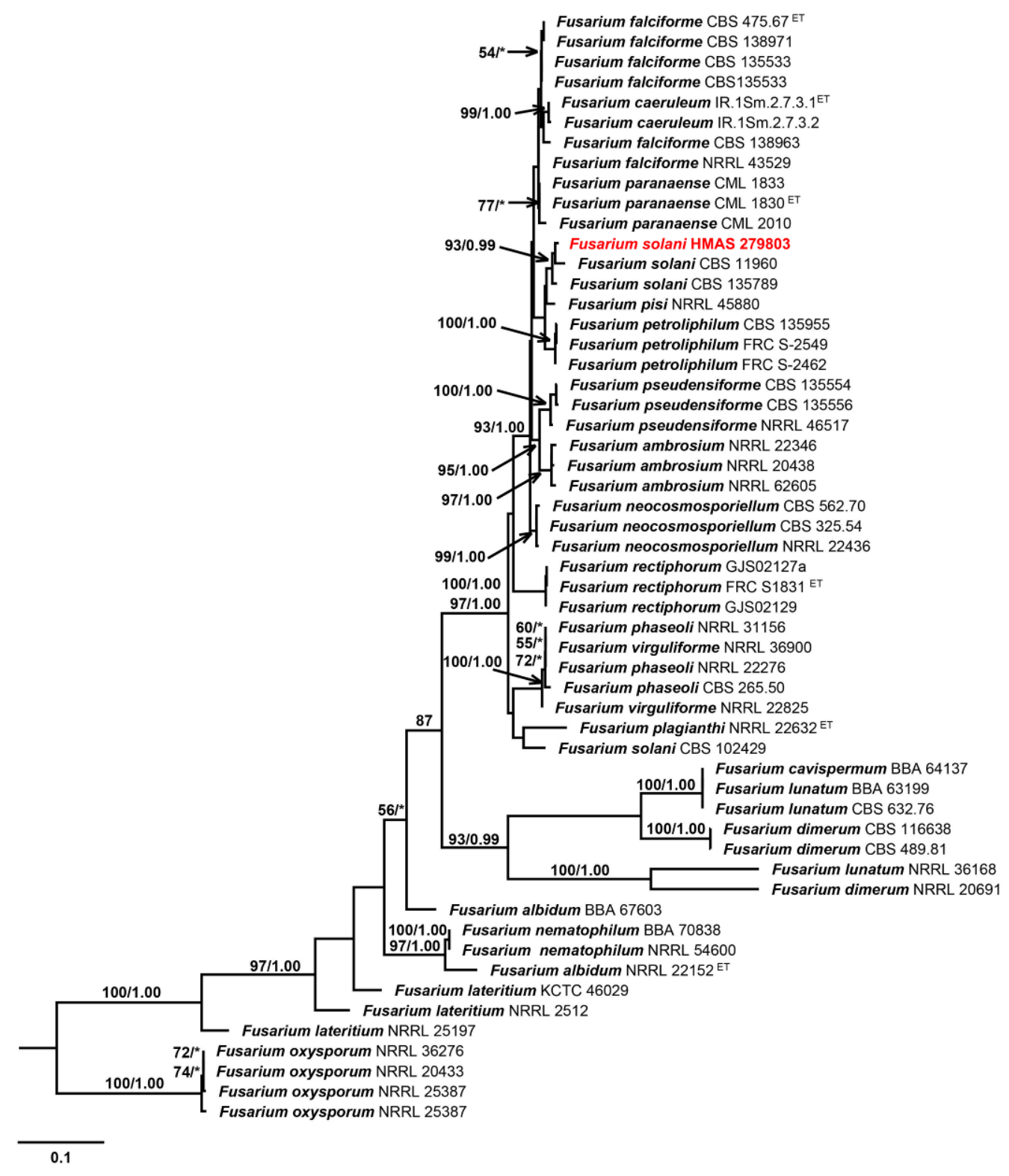

Fig. S3 - Phylogram generated by maximum likelihood analysis based on combined ITS, RPB2 and TEF1 sequence data. The tree is rooted with Fusarium oxysporum. Bootstrap values higher than 50\% from RAxML (BSML) (left). ${ }^{\mathrm{ET}}$ indicates ex-living type. Our collection is red. 


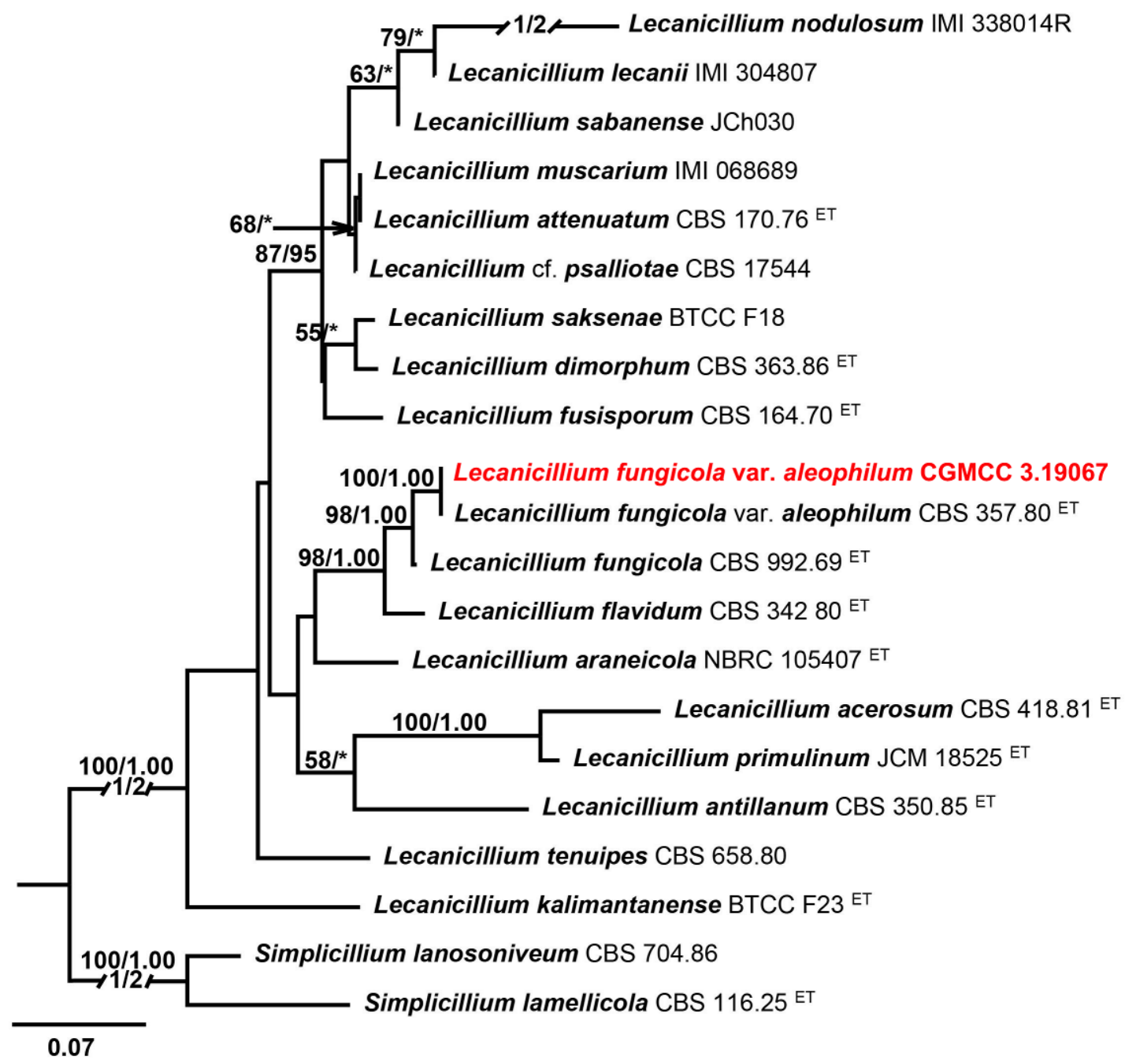

Fig. S4 - Phylogram generated by maximum likelihood analysis based on combined ITS and SSU sequence data. The tree is rooted with Simplicillium lanosoniveum and Simplicillium lamellicola. Bootstrap values higher than 50\% from RAxML (BSML) (left) are given above the nodes. ${ }^{\mathrm{T}}$ indicates type. Our collection in red. 


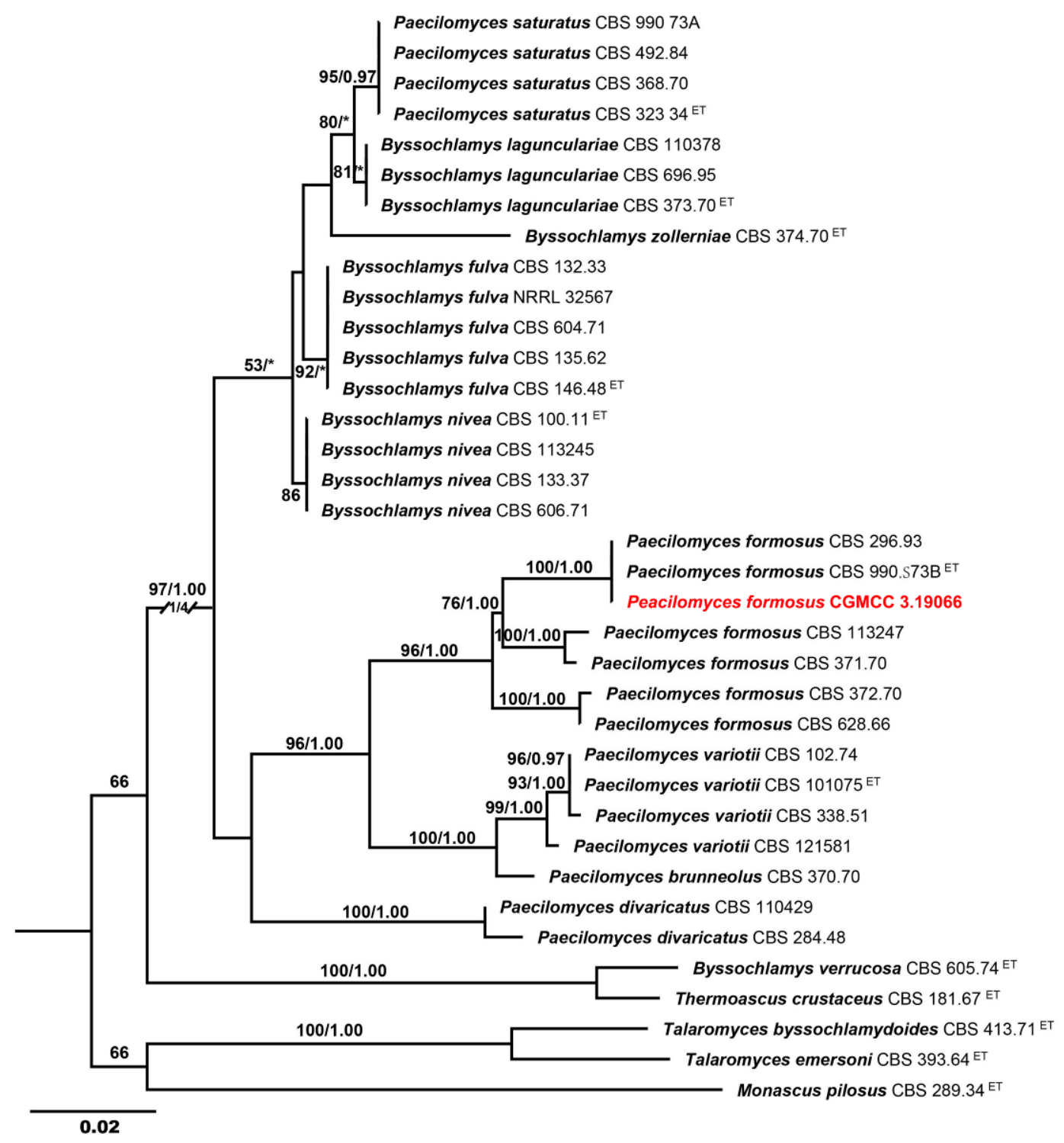

Fig. S5 - Phylogram generated by maximum likelihood analysis based on ITS sequence data. The tree is rooted with Talaromyces byssochlamydoides, Talaromyces emersoni and Monascus pilosus. Bootstrap values higher than 50\% from RAxML (BSML) (left) ${ }^{\mathrm{T}}$ indicates type. Our collection in red. 


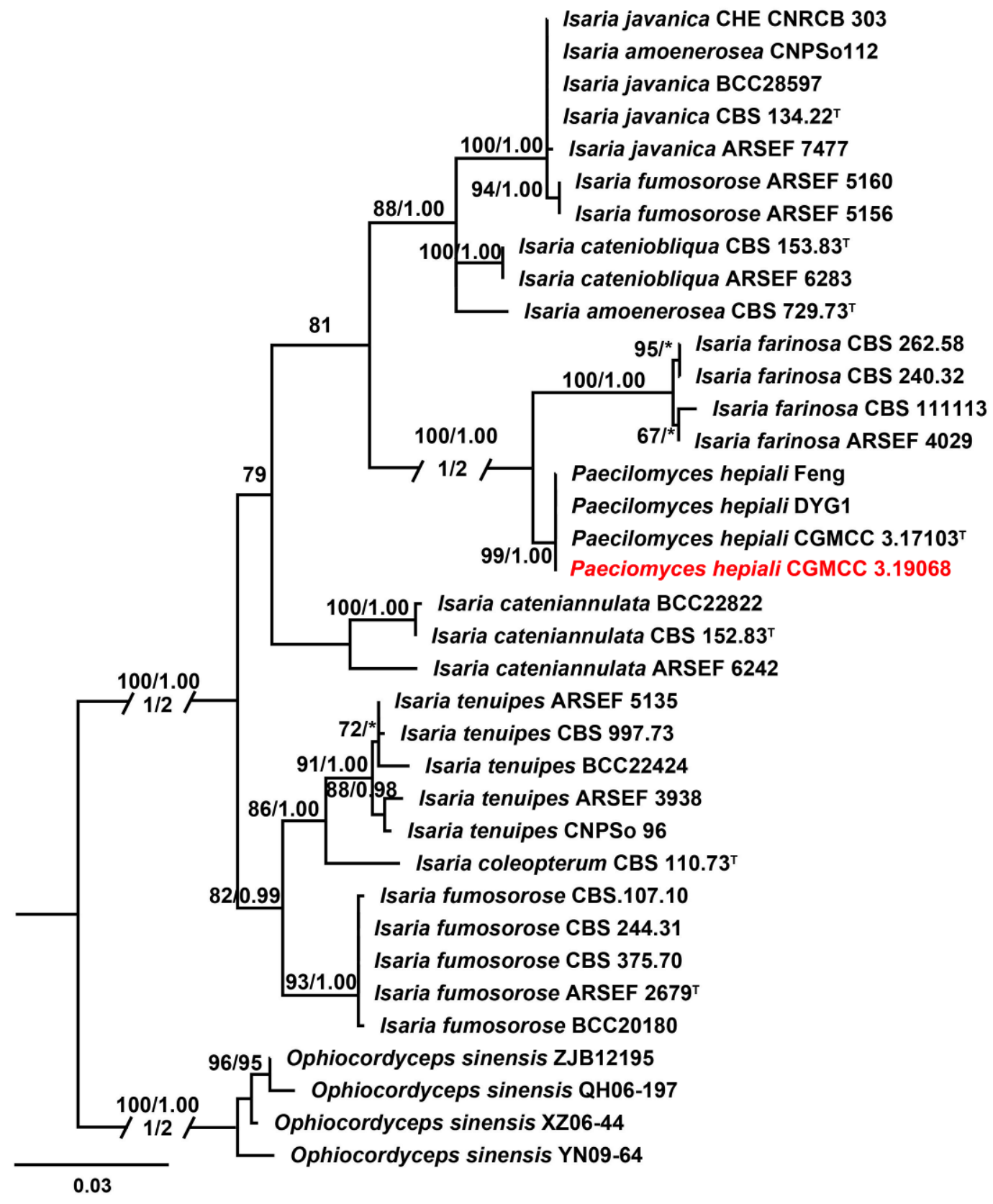

Fig. S6 - Phylogram generated by maximum likelihood analysis based on combined ITS and TEF sequence data. The tree is rooted with Ophiocordyceps sinensis. Bootstrap values higher than $50 \%$ from RAxML (BSML) (left) are given. Bayesian posterior probabilities greater than 0.95 are indicated (BYPP) (right). Asterisks indicate bootstrap values of less than $50 \%$ or Bayesian posterior probabilities lower than $0.95{ }^{\mathrm{T}}$ indicates type. Our collection is red. 


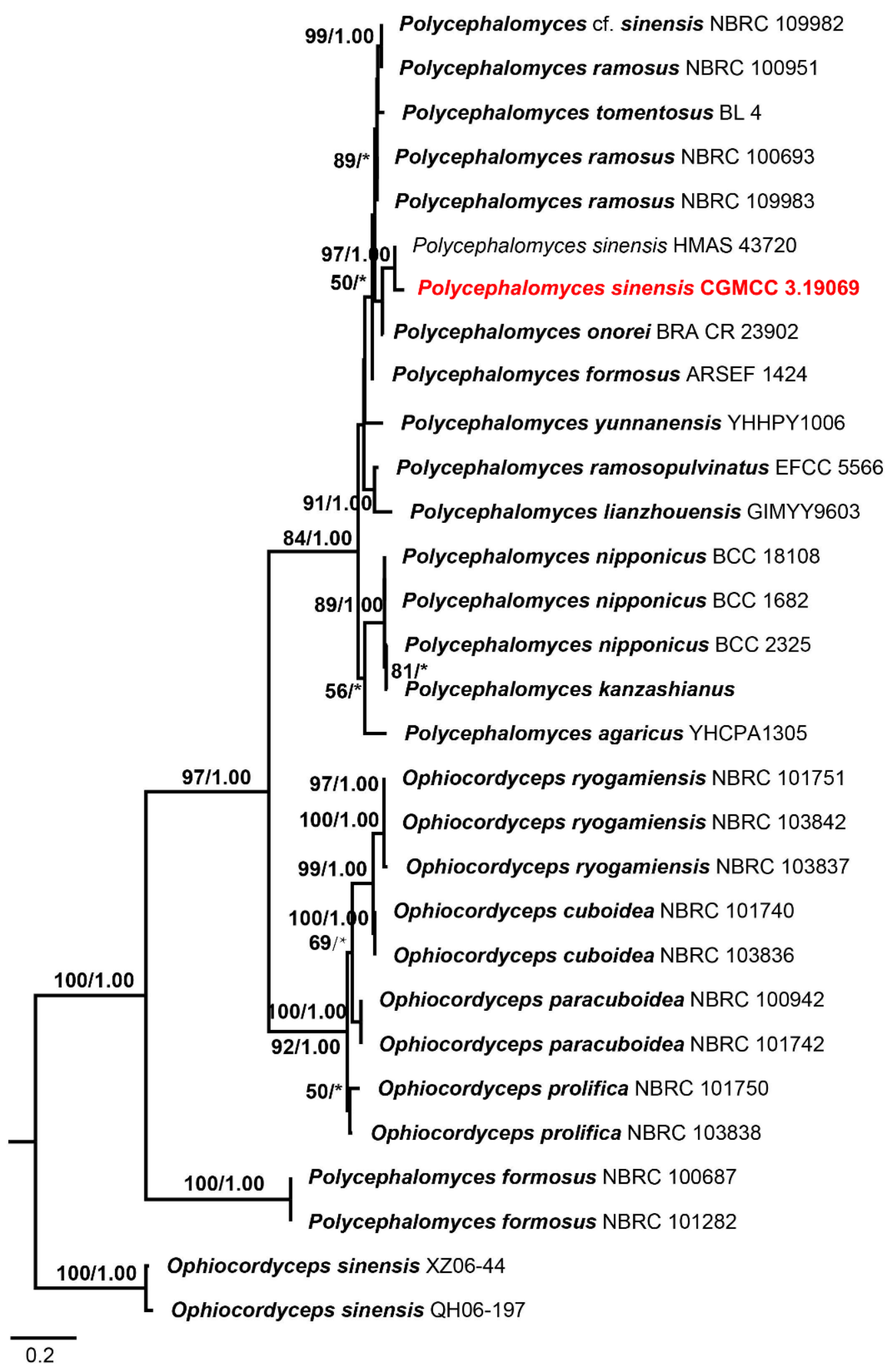

Fig. S7 - Phylogram generated by maximum likelihood analysis based on combined ITS and SSU sequence data. The tree is rooted with Ophiocordyceps sinensis. Bootstrap values higher than $50 \%$ from RAxML (BSML) (left) are given above the nodes. ${ }^{\mathrm{T}}$ indicates type, ${ }^{\mathrm{ET}}$ indicates ex-type. Our collection in red. 


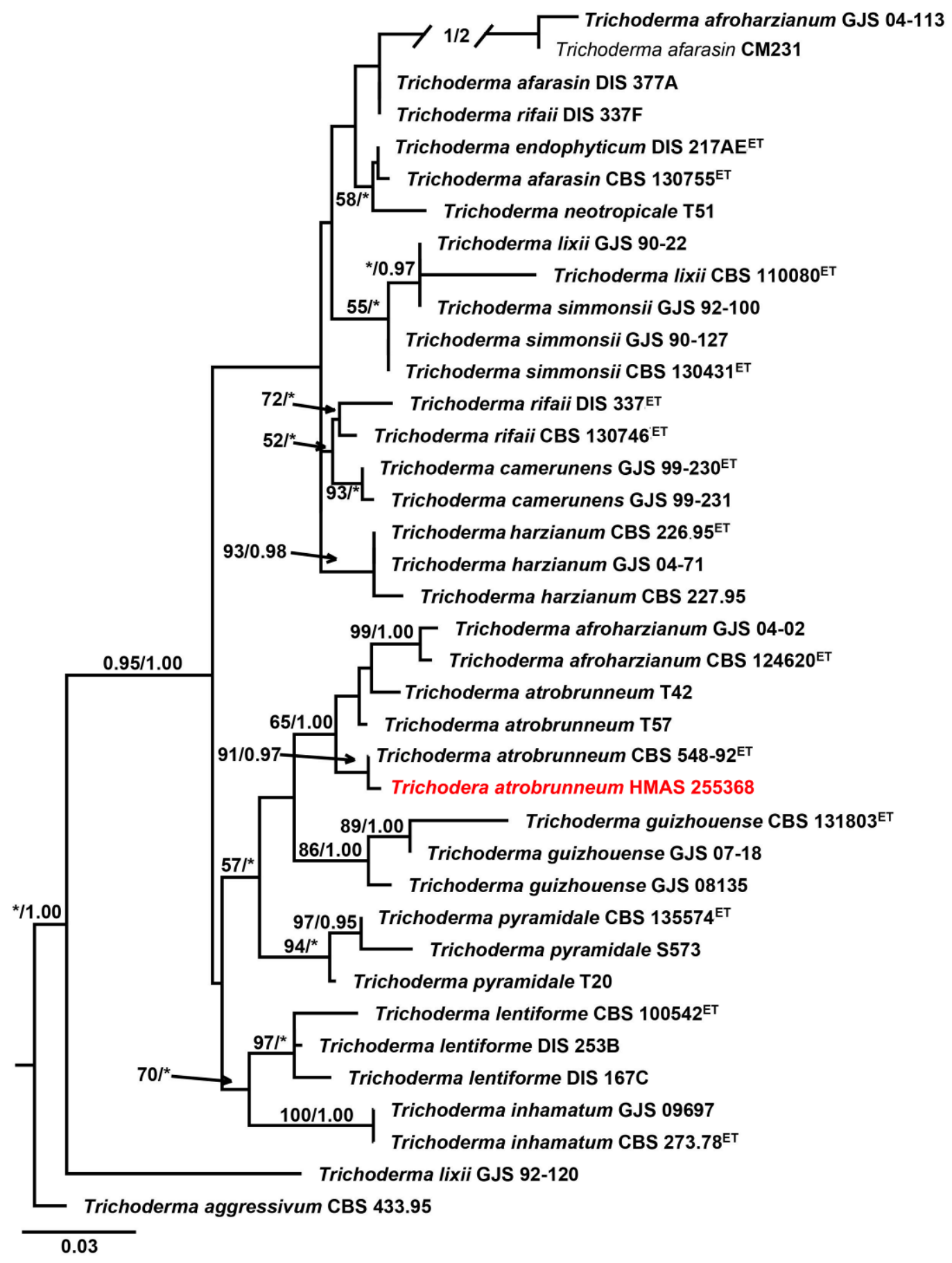

Fig. S8 - Phylogram generated by maximum likelihood analysis based on a combination of ITS and TEF sequence data. The tree is rooted with Trichoderma aggressivum. Bootstrap values higher than 50\% from RAxML (BSML) (left) are given above the nodes. ${ }^{\text {ET }}$ indicates ex-type. Our collection in red. 